\title{
Chemical and Physical Pathways for Fabricating Flexible Superamphiphobic Surfaces with High Transparency
}

\author{
Bichitra Sahoo ${ }^{1}$, Kukro Yoon ${ }^{1}$ (D), Jungmok Seo ${ }^{2,3, *}$ and Taeyoon Lee ${ }^{1, *(D)}$ \\ 1 School of Electrical and Electronic Engineering, Yonsei University, Seoul 03722, Korea; \\ bichitra99@gmail.com (B.S.); kr9875@gmail.com (K.Y.) \\ 2 Center for Biomaterials, Biomedical Research Institute, Korea Institute of Science and Technology (KIST), \\ Seoul 02792, Korea \\ 3 Division of Bio-Medical Science \&Technology, KIST School, Korea University of Science and Technology, \\ Seoul 02792, Korea \\ * Correspondence: jungmokseo@kist.re.kr (J.S.); taeyoon.lee@yonsei.ac.kr (T.L.)
}

Received: 20 December 2017; Accepted: 22 January 2018; Published: 25 January 2018

\begin{abstract}
Since the discovery of the self-cleaning properties of the lotus effect, the wetting of surfaces were intensively investigated due to their potential application in many industrial sectors. The transparency of flexible liquid repellent coatings are a major industrial problem and their economic consequences are widely known. Hence, a comprehensive understanding of the developments of flexible and transparent superamphiphobic surfaces is required in a number of technological and industrial situations. In this review, we aim to discuss the progress in the design, synthesis, fabrication techniques, and applications of flexible and transparent superamphiphobic surfaces. We start with an introduction, exploring the contact angles and wetting states for superhydrophilic, superhydrophobic, and superoleophobic surfaces, and continue with a review of the wetting transition of such surfaces. Then, we highlight the fabrication techniques involved for the preparation of flexible and transparent superamphiphobic surfaces. This review also discusses the key issues in the fabrication process and surfaces, and their features in improving durability characteristics and self-repellent performance. Then we suggest various recommendations for the improvement of mechanical durability along with potential future directions towards more systematic methods that will also be acceptable for industry. Finally, we conclude with some challenges and potential applications.
\end{abstract}

Keywords: transparent superamphiphobic; nanoparticle assembly; stretchability; Cassie-Baxter; micropillar; nanocone

\section{Introduction}

The discovery of natural surfaces demonstrating pronounced water repellence (the so-called "lotus effect" or superhydrophobicity) has stimulated extended theoretical and experimental research of the wetting phenomena on rough surfaces [1,2]. Today, the extreme water repellency and unusual self-cleaning properties of the lotus leaf are two of the most studied phenomena in surface science. Superhydrophobic properties haven been observed in plants, birds' feathers, legs of water striders, and other natural objects [3-9]. Recently, liquid repellent surfaces including self-cleaning, anti-smudge, antifouling, and low adhesion characteristics have been extensively examined because of their wide industrial applications in, e.g., automobiles, aerospace, electronics, plastic packaging, and biomedical devices [10,11]. Similarly, Gogolides et al. [12] reviewed the use of hierarchical micro-and nanostructured hydrophilic surfaces. Superhydrophobic surfaces for 
various applications and their incorporation into sensors, microfluidics, and lab-on-chips have also been explored. In addition, transparent, liquid-repellent surfaces can be further used in camera lenses, window glasses, smart screens for electronic displays, and solar panels. Materials of interest for smart screens in electronic displays include soda lime silica, polyethylene terephthalate (PET), and polycarbonate (PC), while those for automotive applications include glass, PC, polydimethyl siloxane (PDMS), PET, nylon, high density polyethylene (HDPE), polyurethane (PU), polymethyl methacrylate (PMMA), and polypropylene (PP) [13]. Furthermore, Ellinas et al. [14] developed a robust and environmentally-stable superamphiphobic micro-nanotextured cyclo-olefin polymer (COP) surface using an $\mathrm{O}_{2}$ plasma chemistry technique. These surfaces possess high surface area, multiple functionality characteristics, and demonstrate a high contact angle $\left(<150^{\circ}\right)$ with a low contact angle of hysteresis $\left(<10^{\circ}\right)$ for a wide range of liquids, from water to hexadecane. A few recent studies discussed the self-formed transparent superamphiphobic coatings for applications such as lab-on-chips, organic light emitting diodes (OLED), energy harvesting, photovoltaic cells, and smart screens for displays. Kontziampasis et al. [15] used a plasma etching process to create roughness on PMMA plates or glass slides coated with PMMA films to demonstrate the combined antireflectivity, super hydrophobicity, and superamphiphobicity characteristics. In general, a photovoltaic device harvests solar energy, converting the incoming photons to charge carriers. To generate electrical power, photovoltaic systems are typically constructed outdoors to maximize light absorption from the sun. The cover glass, which is the top layer of a solar cell, plays the key role in preventing both contamination and damage from a variety of sources, including dust, acid rain, and hail. However, this cover glass can be easily contaminated in various environments while protecting photovoltaic systems. Therefore, the capability of capturing the incident photons and self-cleaning characteristics are both necessary for a solar cell device [16,17]. Du and his coworkers have discussed mechanism and applications of plasma-induced self-formation of polymer nanostructures to fabricate a pattern of sub-100 nm nanostructures without using the nanolithography technique. They emphasized applications of polymer nanostructures in the field of hierarchical nanostructures, liquid repellence, lab-on-chips, OLED, and energy harvesting [18].

Currently there are fabrication methods for antifogging surfaces and structurally-modified flexible transparent antifogging surfaces. Mouterde et al. [19] investigated the antifogging mechanism in model materials designed to mimic natural systems and demonstrated the importance of the texture's features size and shape. They have reported that the small feature size was responsible for enhanced antifogging abilities. Liquid repellent surfaces need sufficient mechanical robustness to be resistant against abrasion and wear. Recent reports indicate that transparent liquid repellent surfaces can also be produced with reasonable robustness, possibly surviving for prolonged periods despite harsh abrasion [20]. The most recent and promising efforts reported the realization of durable, superhydrophobic/superamphiphobic, polymeric surfaces emphasizing the durability tests performed for many important applications, such as self-cleaning, anti-icing, antifogging, and antibacterial action, as well as antireflection and friction control having been reported and reviewed by Ellinas and his co-workers [21]. However, the state-of-the-art on the materials, fabrication techniques, and characterization aspects to make wear resistant liquid-repellent transparent coatings related to translating some of the technologies to large-scale stain-repellent outdoor applications are also discussed. The recent developments also discussed in the literature specify that considerable progress has now been made towards formulating and applying transparent, hydrophobic, and even oleophobic, coatings onto large-scale substrates which can withstand a certain degree of mechanical abrasion [22]. Furthermore, Bayer and his co-workers [23] also discussed superhydrophobic coatings, which demonstrated acceptable levels of wear abrasion and substrate adhesion resistance against pencil hardness, dry/wet scribed tape peel adhesion, and Taber linear Abraser tests. Depending on the surface chemistry and surface texture, this coatings can accumulate large amounts of insect residue on their surfaces. However, this superhydrophobic nanoparticle film is able to eliminate the residual accumulation due to the combination of its hydrophobicity and its relatively low average surface roughness. 


\subsection{Contact Angle and Wetting States}

The applications of a surface are affected by its wetting properties, usually characterized by the behavior of a droplet on it. A suffix of "-philic" or "-phobic" is used when the droplet is attracted to or repelled by the surface, respectively. In combination, four states can be obtained by considering water ("hydro-") or oil ("oleo-") droplets: hydrophilic, oleophilic, hydrophobic, and oleophobic. The wetting state of the droplet on a surface is dependent on both surface chemistry and surface roughness.

Hydrophobicity is usually determined by measuring the contact angle (CA) of a water droplet on a surface, namely, the angle between the surface and the water meniscus near the line of contact. The contact angle of hysteresis (CAH) is the difference in CA when the volume of the drop is increased (advancing angle) and when it is decreased (the receding angle). The greater the CAH (larger hysteresis), the more water drops stick to the surface. Usually, a superhydrophobic surface should have a lower $\mathrm{CAH}$, as this means the droplets will roll off easily [24].

More than 200 years ago, the English physician Thomas Young described the forces acting on a liquid droplet spreading on a plain surface [25]. As shown in Figure 1a, the CA of the droplet $(\theta)$ is related to the interfacial energies at the solid-liquid $\left(\gamma_{\mathrm{SL}}\right)$, solid-vapor $\left(\gamma_{\mathrm{SV}}\right)$, and liquid-vapor $\left(\gamma_{\mathrm{LV}}\right)$ interfaces:

$$
\cos \theta=\frac{\gamma_{\mathrm{SV}}-\gamma_{\mathrm{SL}}}{\gamma_{\mathrm{LV}}}
$$

The above equation, however, is accurate only for completely smooth, chemically-homogeneous surfaces. The principle of superhydrophobicity was first outlined by Wenzel in 1936 [26], and then by Cassie and Baxter in 1944 [27]. Wenzel suggested that, if liquid contact follows the contours of a rough surface, then the roughness should accentuate the intrinsic wetting tendency towards either film formation or an enhanced contact angle. As shown in Figure 1b, in this model, the contact angle is defined by the Wenzel equation:

$$
\cos \theta_{\mathrm{W}}=r \cos \theta_{\mathrm{e}}
$$

where the roughness factor $r(r>1)$ is the ratio of the true surface area of the solid to its horizontal projection, and $\theta_{\mathrm{e}}$ is the equilibrium contact angle on a smooth, flat surface of the same material. A close inspection of the wettability regime shows that roughness promotes wettability $\left(\theta>90^{\circ}\right)$, depending on the chemical nature of the substratum. When the surface contains small protrusions that are filled with air instead of liquid, the wettability enters the Cassie-Baxter regime. The Cassie-Baxter contact angle then is given by a weighted average of the cosines of the contact angles on the solid and air:

$$
\cos \theta_{\mathrm{CB}}=\varnothing_{\mathrm{s}}\left(\cos \theta_{\mathrm{e}}\right)+\left(1-\varnothing_{\mathrm{s}}\right) \cos \theta_{x}
$$

where $\varnothing_{\mathrm{S}}\left(\varnothing_{\mathrm{S}}<1\right)$ is the fraction of the surface present at the tops of the protrusions, $1-\varnothing_{\mathrm{S}}$ is the fraction of the air gaps, and $\theta_{x}$ is the contact angle on air in the gaps and taken to be $180^{\circ}$. As shown in Figure 1c, the Cassie-Baxter impregnated state can be defined as [27]:

$$
\cos \theta_{\mathrm{CB}}=\varnothing_{\mathrm{s}} \cos \theta_{\mathrm{e}}+1-\varnothing_{\mathrm{s}}
$$

This state always leads to an increase in contact angle when the droplet bridges the gaps. If the gaps are filled with liquid, then $\theta_{x}=0^{\circ}$, and the contact angle decreases below that of the flat surface. This second case is not the same as the Wenzel case, as the gaps must be filled with liquid before the drop reaches it. Equations (2) and (4) can be combined to produce a more general expression to cover the case when the contacting area itself is not flat (Figure 1d):

$$
\cos \theta_{\mathrm{CB}}=\varnothing_{\mathrm{s}} r\left(\cos \theta_{\mathrm{e}}\right)+\varnothing_{\mathrm{s}}-1
$$

Both Wenzel and Cassie-Baxter theories can only qualitatively predict the contact angle on a rough surface. Further, it is still unclear how to determine when a certain formula should be used. Therefore, 
more definitive guidelines for predicting surface wettability are crucial for designing superhydrophobic surfaces. This issue has been widely studied by several research groups, as will be explained below.

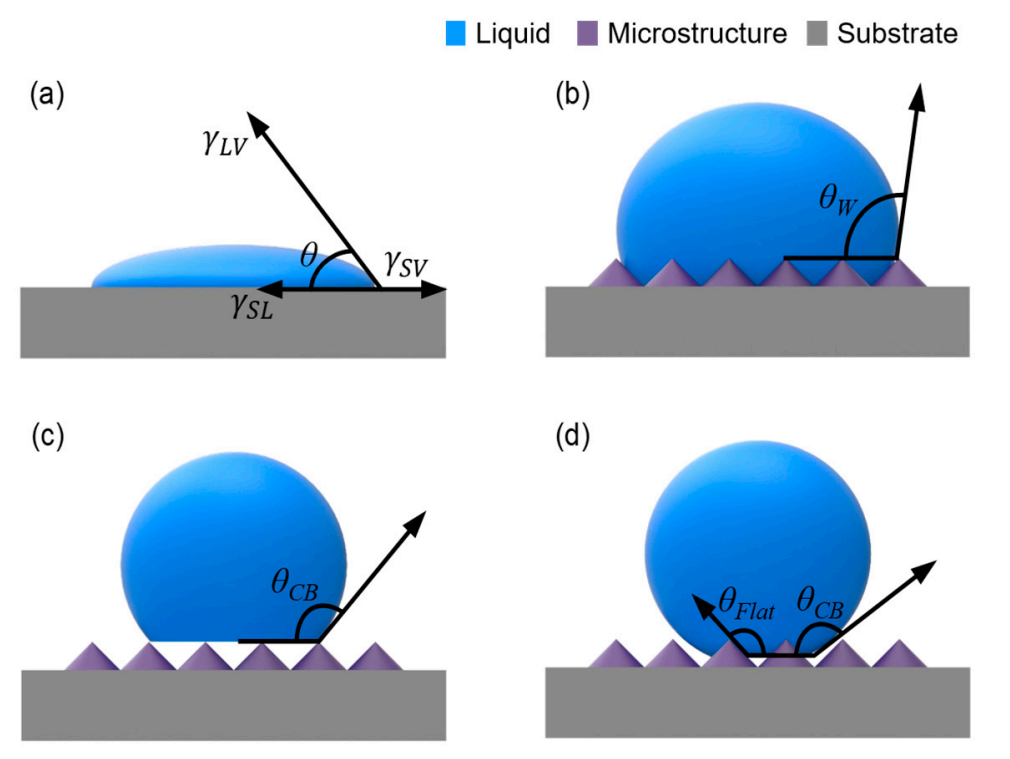

Figure 1. Wetting behavior of a liquid droplet on rough surface: (a) Young's model; (b) Wenzel's model; (c) Cassie's model; and (d) combined Cassie-Wenzel model.

\subsection{Wetting Transitions on Rough Surfaces}

Usually, extremely non-wettable surfaces require both hydrophobic materials and rough surfaces with micro- and/or nanoscale features [28]. When water droplets are dispersed on a surface with the appropriate combination of chemical and physical properties, air pockets can form at the liquid-solid interface so that only the liquid has a small total contact area with the solid, while the rest of the liquid is cushioned by air. It is reported that textured surfaces with sub-micron scale roughness and uniform surface chemistry can be superhydrophobic with very low CAH values [29]. In general, the most energetically-favorable state is the Wenzel state where water penetrates the space between the rough protrusions, resulting in full wetting of the solid phase.

Figure 2a-f illustrate the difference between the Wenzel and Cassie-Baxter types of wetting on micro- and/or nanoscale rough surfaces. Both Wenzel and Cassie-Baxter types exhibit the same contact angle, but completely different behaviors in terms of water adhesion. As shown in Figure 2a, water is filled into the micro- and nanostructures, demonstrating high CA and CAH. In the Wenzel state, the penetration of water in rough asperities of the surface induces pinning effects that dramatically increase the solid-liquid adhesion [26]. Similarly, in the Cassie-Baxter state (Figure 2b), the air entrapment on the solid-liquid contact causes a dramatic reduction in adhesion, high CA, and low $\mathrm{CAH}$ since air can be regarded as a very hydrophobic substance. As a result, the droplets tend to roll off easily [27]. As shown in Figure 2c (Wenzel filled nanostructures), water is impregnated inside the nanostructures on the surfaces in the Wenzel state. However, for the Cassie filled microstructures (Figure 2d), water impregnated the microstructures in the Cassie state. Many researchers have used the presence of hybrid states to explain particular water adhesion behaviors on surfaces with dual-scale roughness, e.g., Cassie-Baxter in the microscale and Wenzel in the nanoscale, or vice versa, or a semi-Cassie-Baxter state where the liquid meniscus partially penetrates the rough features. Similarly, the water-filled Wenzel state with micro/nano structures is illustrated in Figure 2e, and the water-filled Cassie state with nanostructures is demonstrated in Figure 2f [30-33]. 
(a)

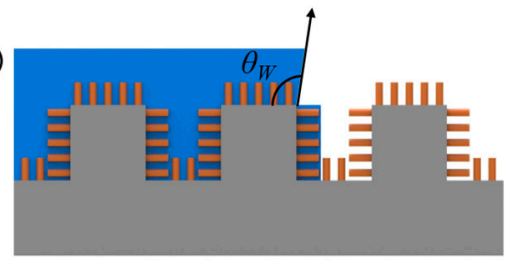

Wenzel state

(c)

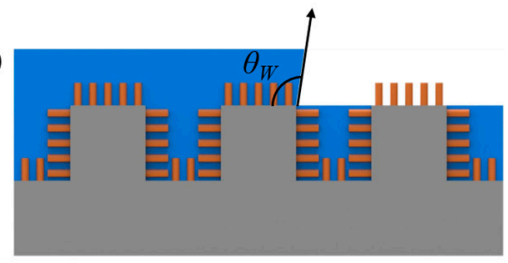

Wenzel filled nanostructure

(e)

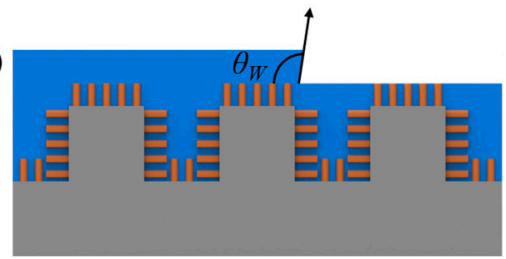

Wenzel filled micro/nanostructure
Liquid Micro/nano structure Substrate

(b)

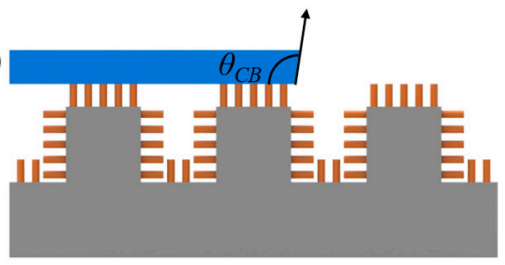

Cassie state

(d)

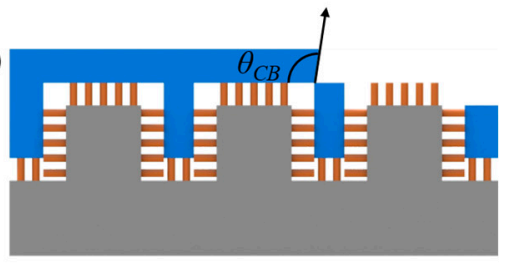

Cassie filled microstructure

(f)

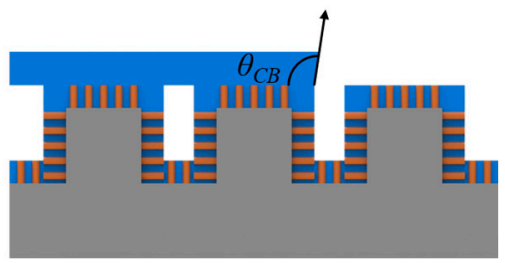

Cassie filled nanostructure

Figure 2. Schematic representation of possible wetting states on a micro/nanoscale rough hierarchical superhydrophobic surface: (a) Wenzel state; (b) Cassie state; (c) Wenzel filled nanostructure; (d) Cassie filled microstructure; (e) Wenzel filled micro/nanostructure; and (f) Cassie filled nanostructure.

Engineering transparent surfaces that actively repel water [34], oil [35], low-surface-tension liquids [36], and/or organic liquids have many applications in the fields of fluids [37,38], chemical shielding [39], stain-proof coatings [40,41], membrane technologies [42], and antifouling coatings [43]. During the past decade, superhydrophobic surfaces have received much attention because of the challenge of understanding their basis [1,44-46] and the many technological implications they possess [47-51]. Most of the applications require coatings for large surfaces. In recent years, the focus has shifted towards industrial applications and multi-functionality in the fabricated surfaces (including reflection and transparency switchability) [52,53]. However, many strategies to hydrophobize surfaces are not easily applicable to large surface areas [54]. Therefore, it is necessary to find new approaches for the preparation and application of hydrophobic and mechanically-durable stable coatings for large multipurpose areas [55]. In addition to mechanical durability, optical transparency with both self-cleaning and antireflection features would be very beneficial in many applications, such as solar cells, LEDs, and optical lenses, since highly-transparent and water-repellent surfaces can improve the device performance by eliminating the reflection losses and lower the maintenance cost due to the self-cleaning property. However, the challenge in preparing such multifunctional surfaces is to balance both surface roughness and transparency of the antireflection coatings [56,57].

While it is difficult to cover all of the relevant literature, here we focus on developments during the last 15 years on flexible, transparent, and superhydrophobic surfaces. This review covers several strategies and fabrication techniques. The fabrication methods include the pattern transfer technique, assembly of nanoparticles, and the thiol-ene reaction. Next, we discuss the applications of transparent and flexible superamphiphobic surfaces. Finally, our recommendations and future works are mentioned. 


\section{Approaches to Creating Transparent and Flexible Superamphiphobic Surfaces}

A number of fabrication techniques have been developed to obtain superhydrophobicity and superoleophobicity. Realizing transparency on a superhydrophobic surface will clearly expand the application to solar cell panels, self-cleaning lenses, and window glasses to impart self-cleaning or anti-dust properties. However, a rougher surface tends to have a lower transparency. Surfaces that are highly transparent, flexible, and superamphiphobic requires an optimized surface roughness that can trap air underneath (Cassie-Baxter state) and a passivation layer with a low surface energy coated on the rough texture. There are three general approaches to fabricate flexible superamphiphobic surfaces with high transparency: transparent coatings using pattern transfer to polymers, nanoparticle assembly, and the thio-ene reaction.

Whereas glass is the most common optical material for lenses, architectural windows, and so forth, transparent polymers, such as PC and PMMA, are also of great engineering importance. PC and PMMA are used for a wide range of applications including aircraft canopies, bulletproof windows, solar cell panels, laptop computer screens, and many high-performance optical, electronic, and medical devices. $\mathrm{SiO}_{2}$, thin films of $\mathrm{ZnO}$ (Zinc Oxide), and indium tin oxide (ITO) are also of interest for various applications. Table 1 provides a summary of reported works on transparent superhydrophobic surfaces [58-64] fabricated on transparent polymers. However, stretchability and flexibility are also important for many industrial applications. Now we proceed to discuss the fabrication and application of transparent and flexible/stretchable superamphiphobic surfaces.

Table 1. Summary of various materials and methods reported for fabrication of transparent superhydrophobic surfaces.

\begin{tabular}{|c|c|c|c|c|c|c|}
\hline Substrate & Structure & $\begin{array}{l}\text { Fabrication } \\
\text { Method }\end{array}$ & Surface Post Treatment & $\begin{array}{c}\text { CA/CAH } \\
\left({ }^{\circ}\right)\end{array}$ & $\begin{array}{c}\text { Transmission } \\
(\%)\end{array}$ & Ref \\
\hline PMMA & Substrate itself & Plasma etching & Fluorocarbon $\left[\mathrm{C}_{4} \mathrm{~F}_{8}\right]$ & $152 / 5$ & - & {$[58]$} \\
\hline PET & Substrate itself & Plasma etching & $\begin{array}{c}\text { Fluorosilane } \\
{\left[\mathrm{CF}_{3}\left(\mathrm{CF}_{2}\right)_{8}\left(\mathrm{CH}_{2}\right)_{2} \mathrm{Si}\left(\mathrm{OCH}_{3}\right)_{3}\right]} \\
\text { Fluorosilane }\end{array}$ & 150 & 90 & [59] \\
\hline PET & $\mathrm{SiO}_{2}$ & Spin coating & $\begin{array}{l}\text { [Heptadecafluro-1,1,2,2- } \\
\text { tetrahydrodecyl } \\
\text { triethoxysilane] }\end{array}$ & $150 / 2$ & 80 & {$[60]$} \\
\hline PDMS & Substrate itself & Lithography & $\begin{array}{c}\text { Fluorosilane [Perflurodecyl } \\
\text { trichlorosilane] }\end{array}$ & $145 / 30$ & - & {$[61]$} \\
\hline PC & $\begin{array}{c}\mathrm{SiO}_{2} \\
\text { fluorocarbon }\end{array}$ & $\begin{array}{l}\text { Microwave } \\
\text { Plasma }\end{array}$ & - & $156 / 5$ & 90 & [62] \\
\hline PET & $\mathrm{Al}_{2} \mathrm{O}_{3}$ & Dip coating & $\begin{array}{c}\text { Fluorosilane } \\
\text { [Heptadecafluro } \\
\text { decyltrimethoxy silane] }\end{array}$ & 150 & 90 & {$[63]$} \\
\hline PDMS & Substrate itself & Lithography & $\begin{array}{c}\text { Fluoropolymer } \\
{\left[\mathrm{CF}_{3}\left(\mathrm{CF}_{2}\right)_{5}\left(\mathrm{CH}_{2}\right)_{2} \mathrm{SiCl}_{3}\right]}\end{array}$ & $153 / 18$ & 94 & {$[64]$} \\
\hline
\end{tabular}

\subsection{Flexible Nonwettable Transparent Coating from the Pattern Transfer Technique}

\subsubsection{Wet Etching}

Super-repellent surfaces with special flexibility characteristics and transparency have recently attracted a great deal of attention in material science. Tsui et al. [65] used a facile fabrication method to prepare flexible plastic antireflective (AR) films with three-dimensional nanocone arrays. The flexible nanocone films were fabricated by molding PDMS with anodic alumina inverse-nanocone arrays fabricated on aluminum substrates. Figure 3a illustrates the fabrication process of this flexible and superhydrophobic surface.

A schematic of the nanocone film is illustrated in Figure 3a. In Figure 3a(i), an electrochemicallypolished clean $\mathrm{Al}$ foil was imprinted using a silicone stamp with hexagonally-ordered nano-pillars with a height of $200 \mathrm{~nm}$ and a tunable pitch of $500 \mathrm{~nm}$ to $2 \mu \mathrm{m}$, in order to produce a nano-indentation 
array on the surface of the $\mathrm{Al}$ foil. To obtain I-cone arrays of PDMS film, anodization and wet etching processes were carried out with the imprinted $\mathrm{Al}$ foil in an acidic solution. Thereafter, a 50-nm thick $\mathrm{Au}$ layer was sputtered on the I-cone array surface as an anti-sticking layer between the PDMS and I-cone arrays. As shown in Figure 3a(ii), a premixed PDMS mixture was then poured onto the Au-coated template, followed by degassing and curing processes. In Figure 3a(iv), the PDMS film with nanocone arrays was peeled off from the template. The nanocone film displayed a water contact angle of $152^{\circ}$ (Figure 3b). Figure 3c demonstrates the flexibility of the PDMS nanocone film. The FESEM (Field Emission Scanning Electron Microscopy) image of the fabricated Au-coated I-cone arrays (1 $\mu \mathrm{m}$ pitch and $1 \mu \mathrm{m}$ depth) is shown in Figure 3d. Later, this PDMS nanocone film was attached to CdTe to prepare a photovoltaic solar cell. As shown in Figure 3e, the reflectance spectra of the bare CdTe device was reduced by $4 \%$ at any given wavelength by using the $3 \mathrm{D}$ nanocone film. This reduction is attributed to the shape of the tapered nanocones, which provides a gradual change in the refractive index from air to PDMS. Overall, this is a highly versatile new process to fabricate AR layers cost-effectively.

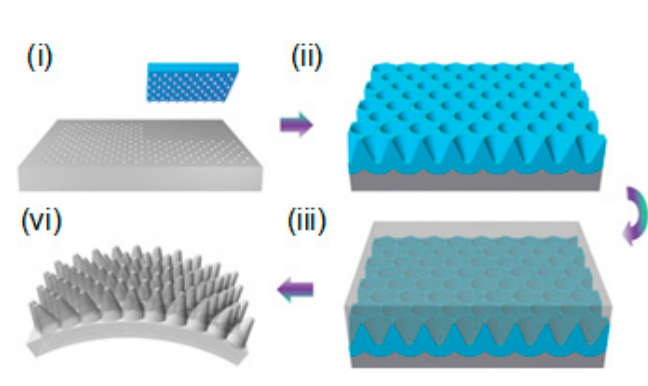

(a)

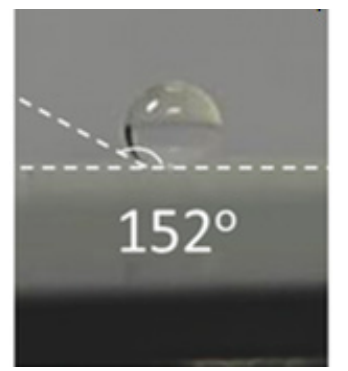

(b)

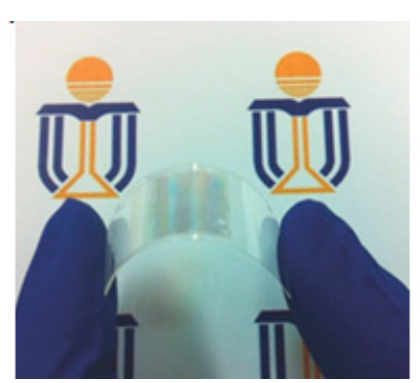

(c)

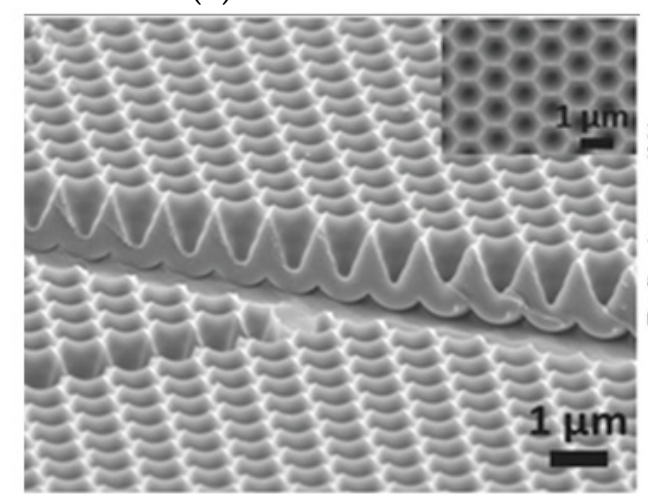

(d)

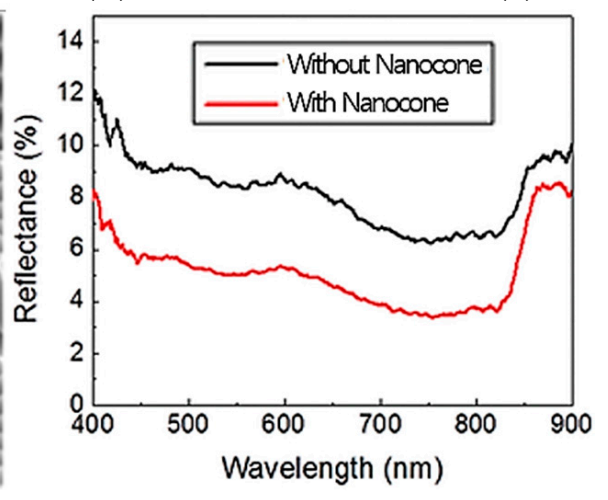

(e)

Figure 3. (a) Schematics of a nanocone film of an Au-coated template and PDMS nanocones: (i) A Si mold with hexagonally-ordered nanopillars was used as an imprint mold with four nanoimprint steps; (ii) An I-cone array fabricated by a multi-step anodization and wet etching process on the imprinted Al foil; (iii) Premixed PDMS poured on an Au-coated template followed by a degassing and curing process; (iv) Regular nanocones on flexible PDMS after peeling-off. (b) A drop of water on the nanocone PDMS film, showing a large contact angle of $152^{\circ}$; (c) Flexible nanocone film; (d) A SEM image of a Au-coated template with a 1- $\mu$ m depth; (e) A reflectance measurement of a CdTe device with and without the nanocone structure. Reproduced from [65] with permission; Copyright Wiley 2014.

Furthermore, if optically-transparent superhydrophobic surfaces can be produced on mechanicallyflexible substrates, such as a film-type material, they can potentially be employed on any curved surfaces for wider practical applications. Unfortunately, there are only a few reports dealing with functional superhydrophobic surfaces with both optical transparency and mechanical flexibility. Kong and his co-authors [66] reported a facile and scalable technique to fabricate self-cleanable superhydrophobic films that possess both optical transparency and mechanical flexibility. Figure $4 a$ shows the fabrication process of the superhydrophobic film proposed in this paper. In the first step a 
porous alumina membrane (PAM) is formed that is then transferred to a polyethylene terephthalate (PET) film. Initially, a photoresist layer (PR) which acts as a sacrificial layer was formed on a silicon wafer by spin-coating and, subsequently, a thick aluminum (Al) thin-film using an electron-beam evaporation technique was deposited. Then, the deposited Al layer was anodized to form PAM by a standard anodization process. The processed specimen was bonded manually to an acceptor substrate, which is prepared by spin-coating the UV-curable polymeric adhesive on a bare PET film, under slightly-pressurized conditions. The polymeric adhesive layer of the bonded specimen was then fully cured by illumination with UV light. Subsequently, the PAM with a residual Al layer was transferred to the acceptor substrate by removing the sacrificial PR layer in an organic solvent. The bottom barrier layer of the PAM was then exposed by fully etching the residual Al layer using an aqueous solution of copper(II) chloride $\left(\mathrm{CuCl}_{2}\right)$ and hydrochloric acid $(\mathrm{HCl})$. Finally, the alumina nanopyramid (NP) structures, which were strongly attached to the fully-cured polymeric adhesive layer, were formed on the PET film through the chemical etching of the barrier layer and inter-pore walls on the PAM in aqueous phosphoric acid solution. In the first step, a $4-\mu \mathrm{m}$ thick photoresist was spin-coated on a silicon wafer, followed by a baking process. Subsequently, $\mathrm{Al}$ deposition was carried out using an electron evaporation technique. The deposited $\mathrm{Al}$ layer was anodized to form a porous aluminum membrane (PAM) layer by a standard anodization process. The specimen was bonded manually to an acceptor substrate, which was prepared by spin-coating a UV curable polymeric adhesive on a bare PET film under slightly pressurized conditions. The polymeric adhesive layer was then fully cured by illumination of UV light. Subsequently, the PAM with Al layer was transferred to the acceptor substrate by removing the photoresist layer. Finally, alumina nanopyramid structures attached to the fully-cured polymeric adhesive layer were fully formed on the PET film by using a chemical etching barrier. Figure $4 \mathrm{~b}$ shows the transparency of the functional film decorated with nanopyramid structures when using an optimized etching time of the PAM. The transmittance of the bare PET film at $550 \mathrm{~nm}(82 \%)$ increased to $88 \%$ after decoration with alumina nanoparticles (NP), due to the scattering effect of the nanoscale surface roughness. However, after modification with the hydrophobic FC coating, the transmittance at $550 \mathrm{~nm}$ decreases to $79 \%$. Figure $4 \mathrm{c}$ shows the film attached to a mobile screen. Such optically-transparent film can be used as a protective cover for solar cell applications, windows, etc. To demonstrate the practical application of the fabricated flexible transparent film, it was used to cover dye-sensitized solar cells (DSSC). The photovoltaic performance before and after the self-cleaning process is shown in Figure $4 \mathrm{~d}$. The power conversion efficiency (PEC) of the bare device ( $4.39 \%$ ) decreased to $4.1 \%$ after covering with the transparent superhydrophobic film, due to the optical loss of light transmitted through the film. After the covered device was coated with dust particles, the PCE value decreased to $2.14 \%$. However, this value was restored to $3.82 \%$ after the self-cleaning process, and the current density $\left(J_{\mathrm{SC}}\right)$ increased to $7.73 \mathrm{~mA} \cdot \mathrm{cm}^{-2}$. Hence, the photovoltaic performance of the DSSC had recovered $93.2 \%$ with respect to that of the DSSC covered with the as-prepared film. In comparison, the PCE of the DSSC without covering with the self-cleanable film recovered only $46.1 \%$ compared to that of the as-fabricated DSSC even after experiencing the same cleaning process. These results suggest that further optimization of the surface geometry would make it possible for the proposed superhydrophobic film to be considered as a self-energy-saving method by recovering the energy efficiency. 


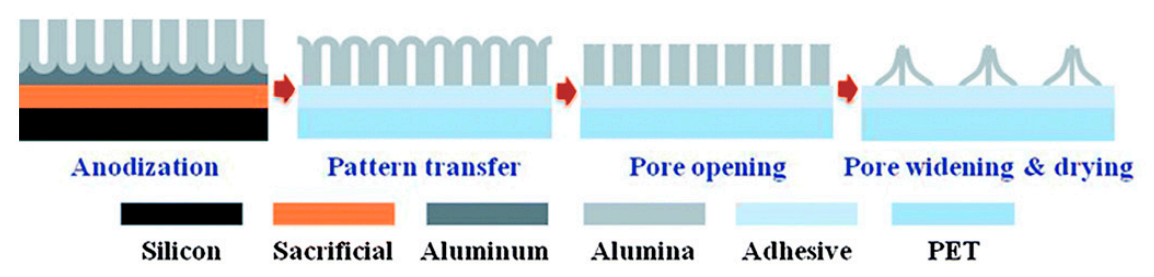

(a)

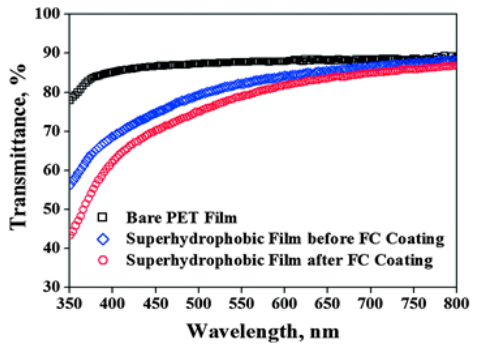

(b)

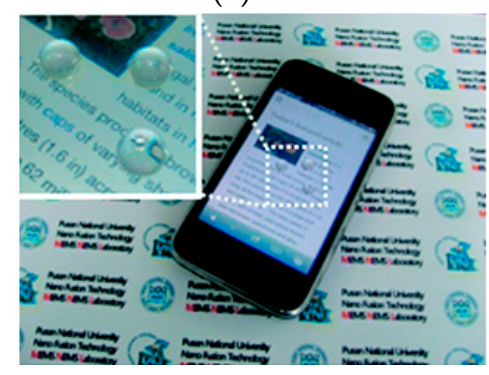

(c)

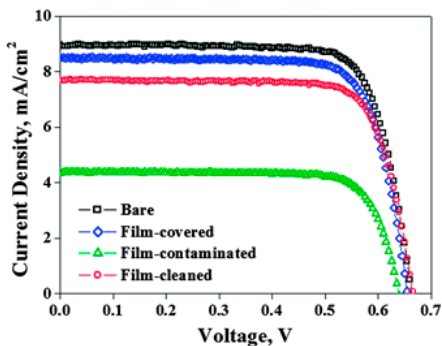

(d)

Figure 4. Fabrication of the proposed flexible, transparent, and self-cleanable superhydrophobic film: (a) Fabrication procedures; (b) optical transmittance of the fabricated superhydrophobic film in the wavelength range of $350-800 \mathrm{~nm}$; (c) the flexible film attached to the screen of a mobile phone. (d) $J-V$ curves obtained from DSSC under the different film conditions for solar cell application. Reproduced from [66] with permission; Copyright Royal Society of Chemistry 2014.

\subsubsection{Plasma Etching}

Arrays of nanostructures, such as nanocones, nanotips, nanopillars, and nanowires, have attracted great attention recently due to their notable characteristics, such as broadband antireflection and light trapping properties [67-69], strong hydrophobicity [70-72], and high surface area [73]. These arrays have applications in photonic [74] and photovoltaic devices [75], biological and chemical sensors [76], and self-cleaning surfaces [77]. The arrays of metal nanostructures also have the potential as blackbody materials due to their broadband antireflective and light absorption properties, which are induced by the excitation of localized surface plasmon resonance and their interactive coupling [78,79]. Incorporating the excellent optical properties of metal nanocone arrays into devices and components requires the development of simple, rapid, and scalable fabrication methods. Toma et al. $[80,81]$ demonstrated a new method comprised of colloidal lithography and oxygen plasma etching for creating two-dimensional periodic gold nanocone arrays on flexible Teflon films. The fabrication process is illustrated in Figure 5a. As shown in Figure 5a(i), a colloidal monolayer is prepared on Teflon film by spin coating a solution of polystyrene beads. After drying the solvent, the surface was etched by oxygen plasma, during which the nanocone structures were formed due to both the polystyrene beads and Teflon film underneath being etched simultaneously (Figure 5a(ii,iii)). Then, the Teflon nanocones are coated with a thin layer of gold $(\mathrm{Au})$ using a thermal evaporator, as illustrated in Figure 5a(iv). Both the top- and side-view images are given for the representative samples at each preparation step during the fabrication. As shown in Figure $5 b$, the surface of the Teflon film changed from glossy transparent to matte-white, indicating strong light scattering by the nanostructures. Figure 5c shows the SEM image representing a large-area view of the gold nanocone arrays, clearly showing that the nanocone array is comprised of multiple oriented domains of hexagonally-packed nanocones. A photograph of a water droplet with a volume of $10 \mu \mathrm{L}$ on the gold nanocone array is inserted in Figure 5c. The contact angle was measured to be $145^{\circ}$, which is quite close to a value of a superhydrophobic surface, $150^{\circ}$, indicating that the structure of the nanocone array has superhydrophobicity due to trapped air pockets in the interspaces among the nanocones. 
(a)
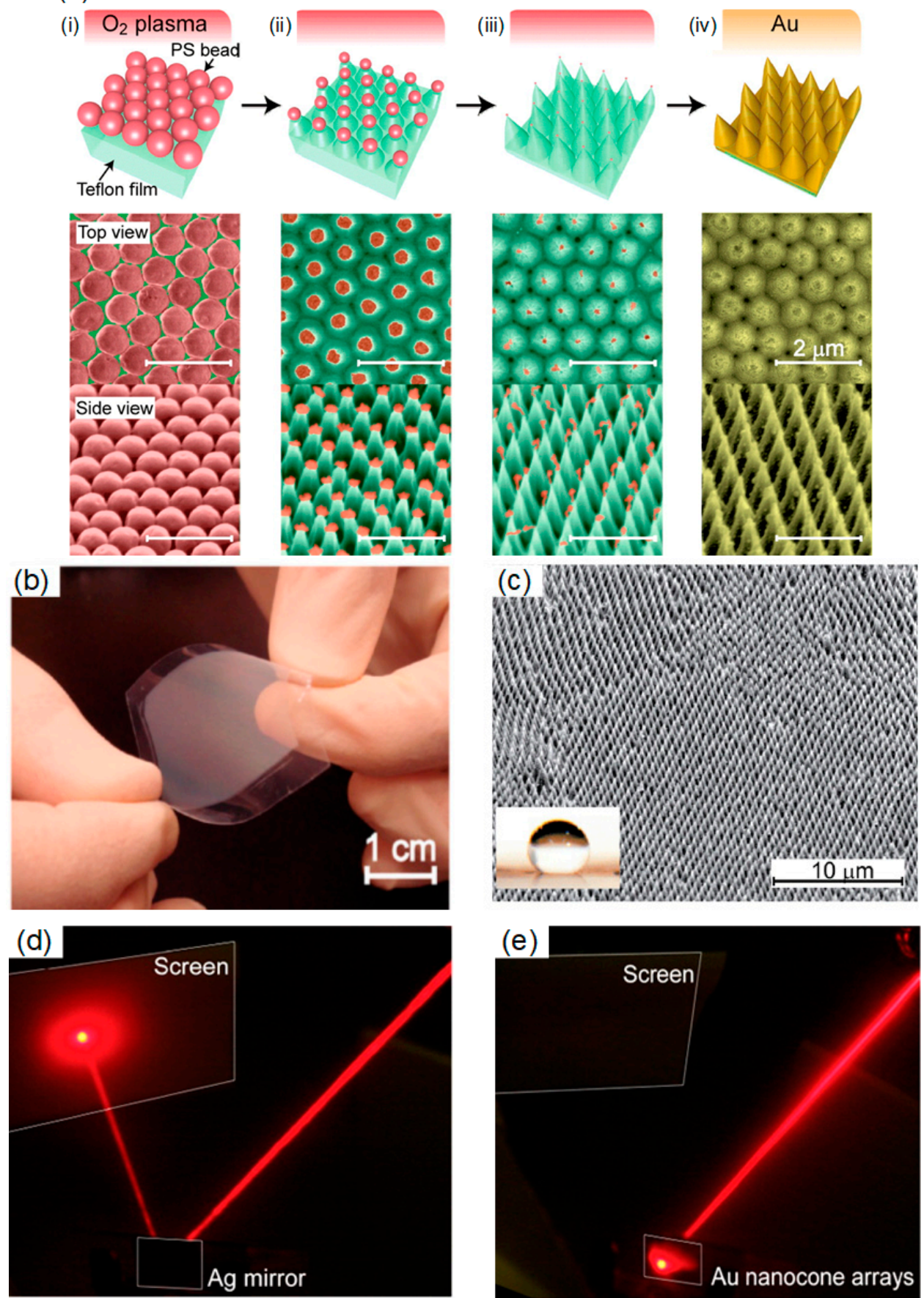

Figure 5. (a) Top row: schematic illustration of the fabrication process (top row): (i) Fabrication of a PS bead monolayer on a flexible Teflon film; (ii,iii) Formation of nanocone arrays by simultaneous plasma etching PS beads and Teflon film; (iv) Deposition of gold thin film on the Teflon nanocone array. Colored SEM images of the corresponding samples in both the top (middle row) and tilted (bottom row) views. The scale bar is $2 \mu \mathrm{m}$ in all the SEM images. (b) Photographs of nanocone arrays on the Teflon film. (c) SEM image of the gold nanocone array in tilted view. Photographs showing the laser beam path reflected by (d) a silver mirror and (e) a gold nanocone array. Reproduced from [80] with permission; Copyright ACS 2013. Reproduced from [81] with permission; Copyright ACS 2014. 
The antireflective properties of the gold nanocone arrays prepared with polystyrene nanobeads and the plasma-etching process is demonstrated in Figure 5d,e, in which a He-Ne laser with wavelength of $633 \mathrm{~nm}$ was incident on, and reflected by, a silver mirror and gold nanocone arrays, respectively. While almost no light is reflected from the nanocone array to form a spot on the screen, the flat silver film exhibited strong reflection.

\subsubsection{Soft Lithography}

Nowadays, surface microfluidics is an emerging liquid handling technology that enables control of individual droplets on an open surface [82]. Since surface microfluidics is open to the atmosphere, individual droplets can be accessed and treated directly. As a result, the samples can be handled without risk of clogging [83]. However, droplets on common substrates usually suffer from surface contamination and losses during manipulation, due to the contact angle hysteresis and contact line pinning. Various approaches have been proposed to avoid this problem over the past decades, including superhydrophobic surfaces (SH) [84-86], superlyophobic surfaces (SLS) [87,88], and slippery liquid-infused porous surfaces (SLIPs) [89]. Among all approaches, microstructured SLS is a promising and versatile platform for planar microfluidics, due to their excellent non-wetting characteristic and low flow resistance for almost any liquid. Wang et al. [90] fabricated stretchable superlyophobic films based on ethylene-vinyl acetate (EVA), which demonstrate highly-flexible, transparent, and adhesive characteristics. They demonstrated the use of stretchable superlyophobic EVA as novel "droplet tweezer" for nearly lossless transfer of water, as well as oil droplets, which enables many potential applications as a surface microfluidic platform.

The fabrication process of SLS EVA film is illustrated in Figure 6a(i-vi). Firstly, a thin positive photoresist and a thick negative photoresist were spin-coated on a Si substrate. The photoresist layer was over-developed after patterning the thick negative photoresist layer to form T-shaped patterns using an ultraviolet mask aligner. Then, by using PDMS as the curable material, the inverse T-shaped patterns on a dual layer resist was transferred to PDMS mold through two successive soft replication processes. After low surface energy treatment of the PDMS mold for easy demolding, a VAE emulsion was poured onto the PDMS mold and cured at $4{ }^{\circ} \mathrm{C}$ to form the structured EVA film. Then, the inverse T-shaped patterns on the dual layer resist substrate were transferred to the EVA film and finally treated with fluorinated self-assembled monolayer (PFTS, F-SAM) at $70{ }^{\circ} \mathrm{C}$ for $10 \mathrm{~min}$ to achieve low surface energy. Due to the excellent flexibility, the as-fabricated EVA film can be decorated on various complex surfaces, and provide ordinary surfaces with universal non-wetting performance. The EVA SLS adhered well to paper, and showed excellent transparency and superoleophobic performance (Figure $6 \mathrm{~b}$ ). The CA of EVA SLS film is $157.6^{\circ}$ for water and $148.8^{\circ}$ for hexadecane, as shown in Figure 6b. As shown in Figure 6c(i-iv), the EVA SLS film could be stretched from 5 to $21 \mathrm{~cm}$ and fully recovered. During the stretching process, the size of microstructures remained nearly constant, while the pitch distance increased, which is shown in Figure 6c(iii,iv). The stretching decreases the solid fraction, which enhances the apparent contact angle $(\theta)$ according to Equation (5). It is seen that the value of $\theta$ decreases with the increasing solid fraction for all the liquids. In addition, by tuning the adhesion force through stretching, the EVA SLS surface can be used as a "tweezer" for lossless droplet transfer for various liquids, including water and oil. This approach is low-cost, very easy to control, highly scalable, and widely applicable; therefore, it may have many interesting applications as a surface microfluidics platform. Diverse hierarchical surface designs have been introduced as superhydrophobic surface structure, because multiscale geometries could greatly improve the superhydrophobicity [91-95]. 


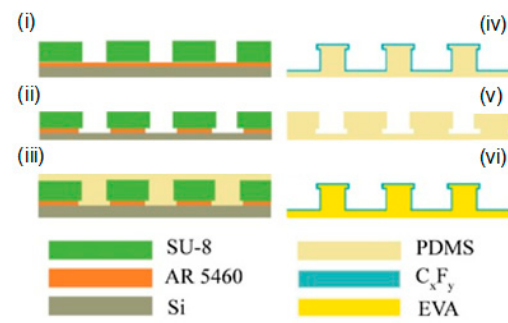

(a)

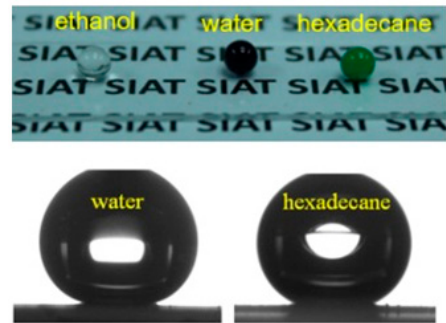

(b)

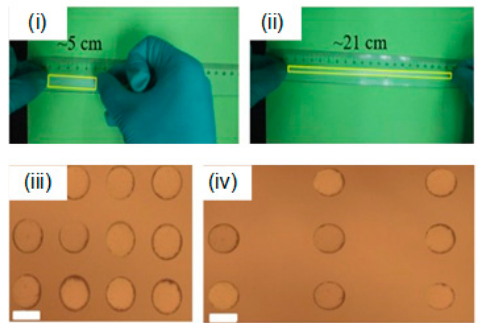

(c)

Figure 6. (a) Fabrication process of the superhydrophobic EVA film: (i) Spin-coating a thick resist (SU-8) followed by a thin resist (ARP-5460) and patterning the SU-8; (ii) Over-developing the ARP-5460 resist to form inverse T-shaped microcavities; (iii) Casting PDMS using standard soft lithography; (iv) Peeling the PDMS intermediate template off the microcavities, and coating $\mathrm{C}_{x} \mathrm{~F}_{y}$ on T-shaped PDMS pillars using $\mathrm{C}_{4} \mathrm{~F}_{8}$ plasma; (v) Casting PDMS onto the PDMS mold and peeling-off; (vi) Pouring EVA film onto the PDMS intermediate mold and peel off after curing, then low surface tension treatment with F-SAM. (b) Transparency of the as-prepared EVA film adhered to paper, and the excellent superhydrophobicity of the EVA SLS film (contact angle: $157.6^{\circ}$ for water and $148.8^{\circ}$ for hexadecane). (c) EVA SLS film: (i) before and (ii) after, stretching, and the corresponding microstructural profiles in (iii) and (iv). All scale bars are $10 \mu \mathrm{m}$. Reproduced from [90] with permission; Copyright Elsevier 2017.

\subsubsection{AAO Template}

Recently, more efforts have been made to demonstrate mechanically-flexible superhydrophobic films using various techniques, such as template-assisted polymer replication and subsequent decoration with nanoscale structures $[96,97]$, and polymer replication with hierarchically-structured templates $[98,99]$. In addition to self-cleaning and mechanical flexibility, optical transparency of the functional surfaces is also an important factor in many fields, such as super-repellent solar panels, anti-fogging glasses, and raindrop-repellent windows. Due to the lack of efficient fabrication techniques, it is difficult to find a simple, cost-effective, and low-temperature method. Overcoming the tradeoff between the critical performance parameters of superhydrophobicity and optical transparency according to the surface roughness levels is also challenging. Hence, Kim and his co-authors [100] reported an anodic oxidation of aluminum technique as the simplest way for fabricating nanoscale features, such as nanopores and nanopillars. The proposed technique is a combination of UV imprinting and AAO technique, as illustrated in Figure 7a. The fabrication of the polymeric micropillar arrays started with the formation of an elastomeric stamp based on a standard soft lithography technique. Using the soft-lithography technique, a photoresist mold was prepared in a silicon wafer substrate. Then, premixed PDMS was poured on the prepared mold, followed by thermal curing at $70{ }^{\circ} \mathrm{C}$ for $1 \mathrm{~h}$. For the UV printing process, microholes on the PDMS stamp were first filled with a UV-curable polymer by manual drop-casting. After UCP filled the PDMS stamp, a polyethylene terephthalate (PET) film was pressed onto it, and the UCP was fully cured by irradiating with UV light $\left(20 \mathrm{~mW} / \mathrm{cm}^{2}, 10 \mathrm{~min}\right)$ through the transparent PET film. The periodic polymeric micropillar arrays were finally transferred to the PET film by carefully separating the PDMS stamp. In particular, various micropillar arrays were fabricated with different interpillar distances $(D)$ of $30-150 \mu \mathrm{m}$, and a step of $30 \mu \mathrm{m}$ with respect to the fixed pillar width of $30 \mu \mathrm{m}$ (P1-P5). Furthermore, for the AAO process, 20- $\mu \mathrm{m}$ thick $\mathrm{Al}$ foil was laminated on a silicon wafer with a sacrificial dry film resist. Then, the Al foil was anodized to form PAM in a beaker containing an oxalic acid solution. The PAM was bonded to the polymeric micropillar arrayed film with a thin adhesive, which was contact printed on the pillars' top surface, followed by UV curing with the same irradiation conditions. During chemical etching of the PAM, the regular size of nanopores was controlled. With further increases in the etching time, the PAM with nanopores was eventually transformed into nanowires with high aspect ratios. These micropillars were used to evaluate the surface wettability and transparency properties under 
various surface morphologies. As shown in Figure $7 \mathrm{~b}$, the sliding angle (Figure $7 \mathrm{~b}(\mathrm{i})$ ) measured on the micro-roughened surface gradually increased, when the edge-to-edge distance increased to $100 \mu \mathrm{m}$ (denoted as P4), and suddenly decreased when the edge-to-edge distance increased to $150 \mu \mathrm{m}$. However, for the case of the hierarchically-roughened surface, the sliding angle gradually increased.

Similarly, the $\mathrm{CAH}$ also decreased for both films, as demonstrated in Figure $7 \mathrm{~b}$ (ii), and their transmittance is demonstrated in Figure 7c. The transmittance of bare PET film is $92 \%$ at a wavelength of $550 \mathrm{~nm}$, which decreased after roughening the surface. The full transmittance curves of the two roughened films at visible wavelength $(400-800 \mathrm{~nm})$ are illustrated in Figure $7 \mathrm{c}(\mathrm{i}, \mathrm{ii})$, showing higher transmittance values in the micro-roughened films than the hierarchically roughened one, for all surface designs. Similarly, photographs of large-area superhydrophobic surfaces fabricated on PET and glass substrates are shown in Figure $7 \mathrm{~d}(\mathrm{i}, \mathrm{ii})$, which clearly demonstrate the wide applications of this cost-effective fabrication method.

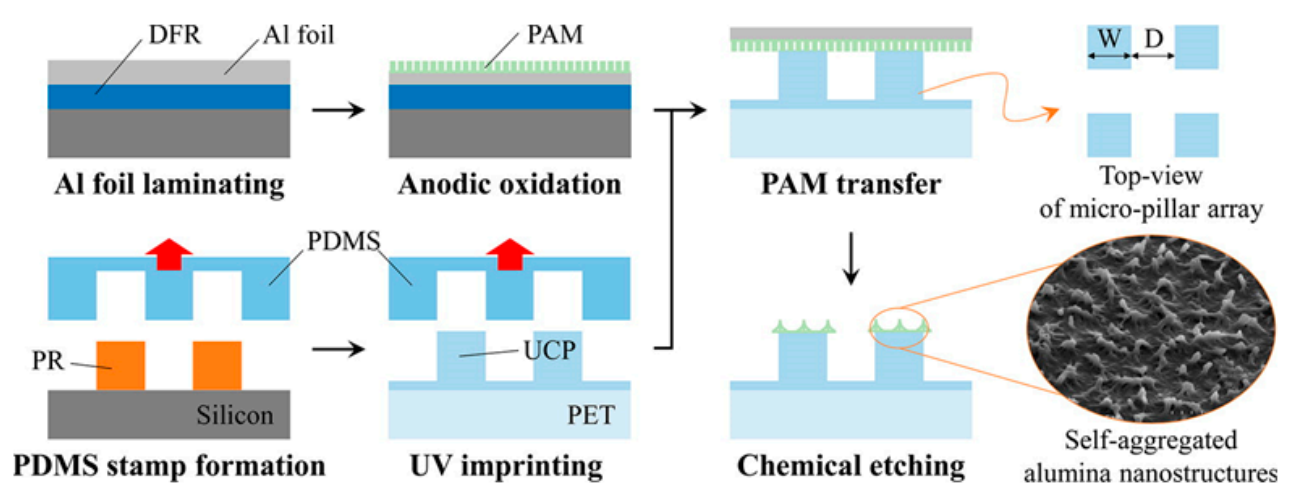

(a)
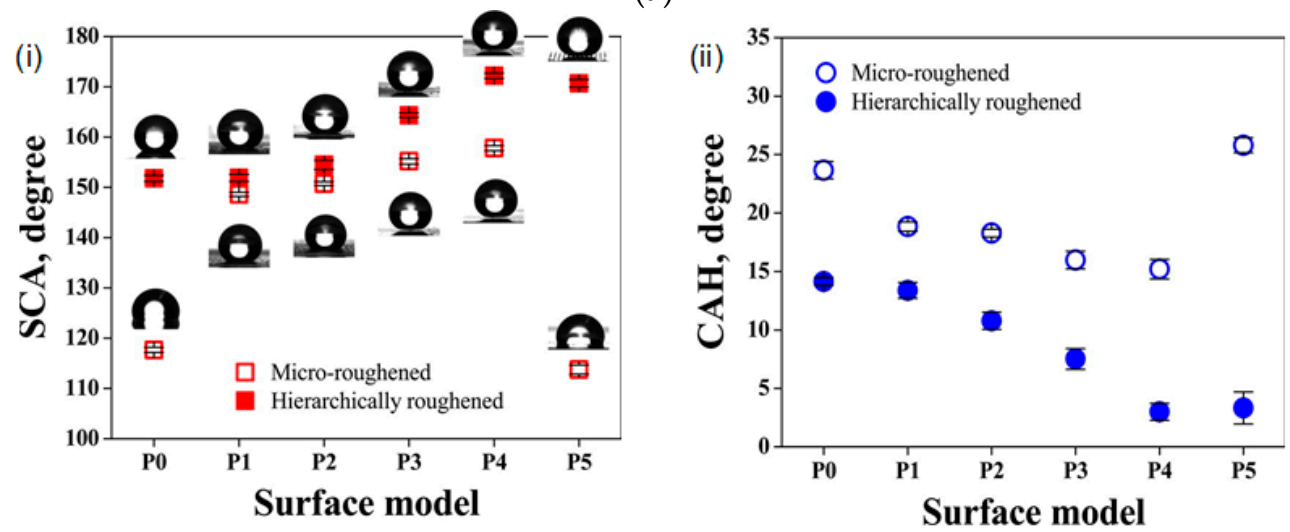

(b)
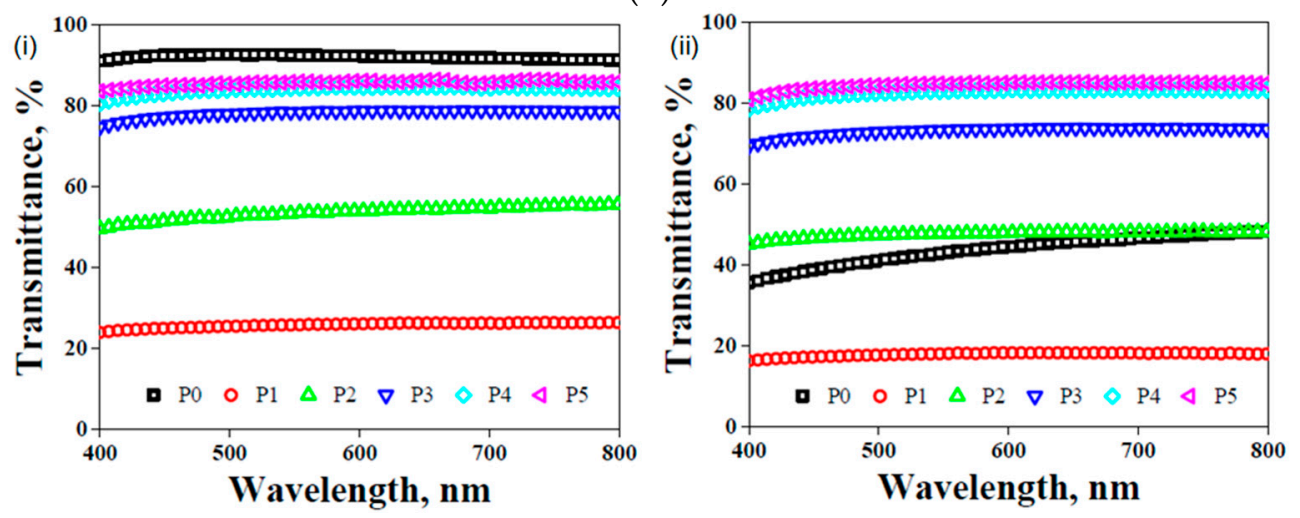

(c)

Figure 7. Cont. 
(i)

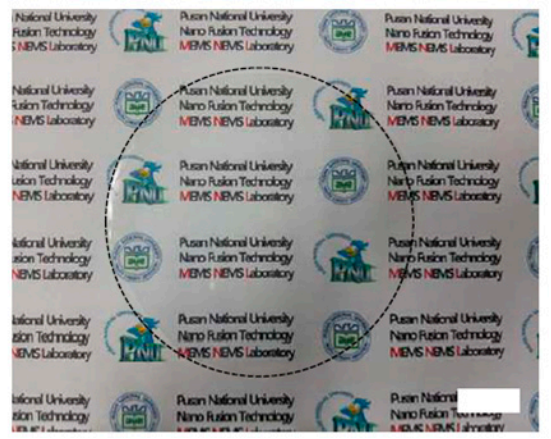

(ii)

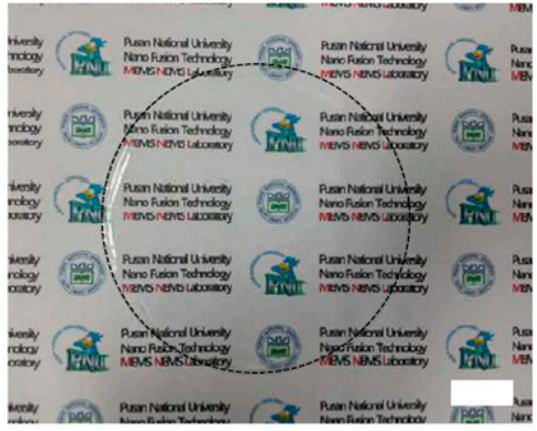

(d)

Figure 7. (a) Fabrication process of the hierarchically-roughened superhydrophobic films; (b) Surface wetting properties of the microroughened and hierarchically-roughened films: (i) static contact angle and (ii) contact angle hysteresis; (c) Transmittance curves measured on (i) the microroughened surface and (ii) hierarchically roughened films at wavelengths ranging from 400 to $800 \mathrm{~nm}$; (d) Photographs of large-area superhydrophobic surface fabricated on (i) PET and (ii) glass substrates (scale bars: $2 \mathrm{~cm}$ ). Reproduced from [100] with permission; Copyright ACS 2015.

\subsubsection{Diffuser Lithography}

The flexible and highly-transparent polymer composites with superamphiphobic properties can repel liquids and contaminants together with the droplet. Thus, they are desired for several applications, such as LEED (Low energy electron diffraction) screen coatings, optical components, outside windows, and anti-contamination walls. There are several ways to fabricate transparent superhydrophobic surfaces with flexibility. For example, by using self-assembled monolayers (SAMs), Im et al. [64] reported robust superhydrophobicity and transparency of a flexible PDMS surface with inverse-trapezoidal microstructure, as shown in Figure 8a. Two consecutive PDMS replication processes were applied. The first one creates the parent PDMS mold from photoresist patterns, while the second one forms new PDMS patterns from the parent PDMS pattern. 3-D diffuser lithography was used to fabricate superhydrophobic surfaces in a large area with a perfectly-ordered microlens array [101]. Figure 8a shows a schematic diagram of the backside 3-D diffuser lithography that was used to fabricate a photoresist mold for duplicating inverse-trapezoidal microstructures by using the soft lithography of PDMS. A negative photoresist was deposited by spin-coating with a thickness of $13 \mu \mathrm{m}$ and an opal diffuser was used during the backside exposure (UV light) on a metal-patterned glass substrate. The inverse-trapezoidal 3D structures were developed according to increasing UV exposure doses of up to $5000 \mathrm{~mJ} \cdot \mathrm{cm}^{-2}$. A SAM (self-assembled monolayer), which can act as an anti-adhesion layer, formed on the surface of the photoresist mold with a silanizing agent (tridecafluoro-1,1,2,2-tetrahydrooctyl trichlorosilane, $\mathrm{CF}_{3}-\left(\mathrm{CF}_{2}\right)_{5}\left(\mathrm{CH}_{2}\right)_{2}-\mathrm{SiCl}_{3}$, Fluka). This SAM layer helped in releasing the replicated PDMS by reducing adhesion between the photoresist mold and the subsequent PDMS replica. For the parent PDMS formation, a mixture of the PDMS base and the curing agent was poured onto the SAM-treated photoresist mold and cured in a convection oven. After peeling the parent PDMS off from the photoresist mold, an $\mathrm{O}_{2}$ plasma treatment was applied to increase the surface energy of the parent PDMS for the following SAM coating. This $\mathrm{O}_{2}$ plasma treatment helped the SAM remain on the surface of the parent PDMS, even after the second PDMS replication process. In the final step, a perfectly-ordered inverse trapezoidal array was attained on the transparent and flexible PDMS elastomer. Further, a Teflon coating on the PDMS trapezoids' surface was performed to offer two advantages: an increased intrinsic contact angle of the solid surface, and an improved transmittance of the PDMS trapezoids' surface. The proposed superhydrophobic surface can be fabricated on a large-sized template with perfectly-ordered microstructures without requiring any etching process. Figure $8 \mathrm{~b}$ demonstrates the transmittance curve of various samples (including a PDMS microlens array and a PDMS trapezoids array) before and after Teflon coating. 
The transmittance of the flat PDMS sample with a thickness of $600 \mu \mathrm{m}$ was approximately $85 \%$ at the visible light wavelength $(400-700 \mathrm{~nm})$. The PDMS including trapezoid arrays with and without Teflon coating showed transmittance values of $72 \%$ and $77 \%$ at the same wavelength, respectively. A Teflon layer can have an anti-reflective property by providing a gradual change of the refractive indices at its interface with the PDMS. Figure $8 \mathrm{c}$ demonstrates the transparency of a PDMS trapezoid array that was fixed on a logo slide. All the letters are visible through the superhydrophobic and transparent PDMS trapezoid samples, but illegible under the superhydrophobic PDMS microlens array. This transparent, flexible, and superhydrophobic surface can be applied to self-cleaning surfaces with arbitrary curvature. Figure $8 \mathrm{~d}$ is a photograph of the PDMS trapezoid sample on one eyeglass lens. In summary, this transparent, robust, and superhydrophobic surface can be implemented with a large range of flexible polymer substrates.

(a)

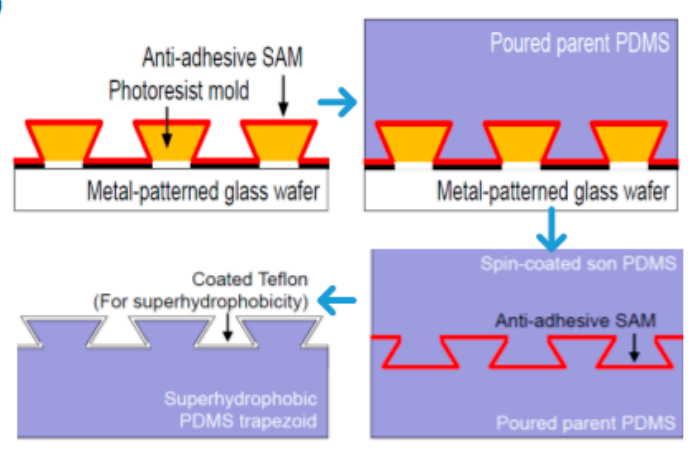

(c)

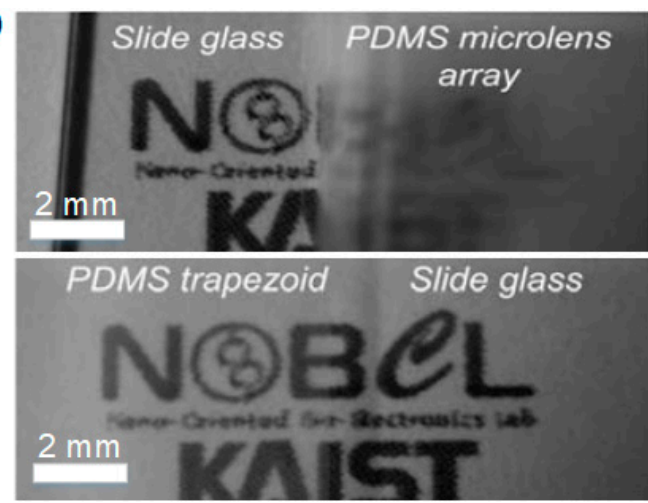

(b)

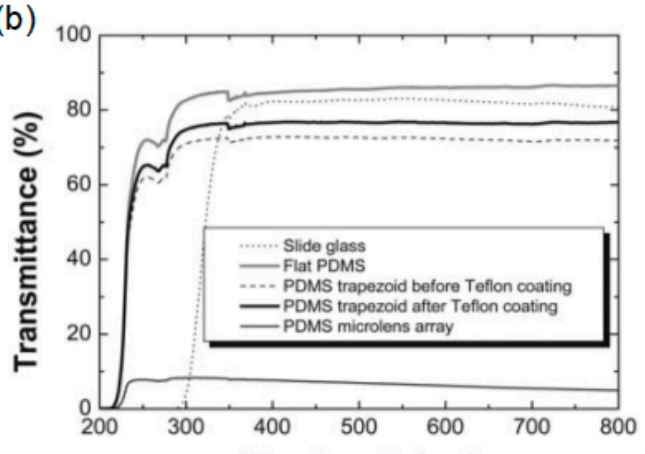

(d)

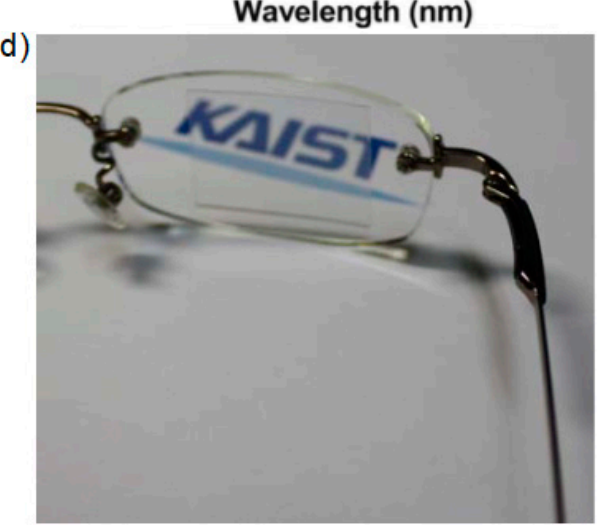

Figure 8. (a) Schematic diagrams of the two consecutive PDMS replication processes; (b) Transmittance characteristics of various samples as a function of the wavelength of the incident light; (c) Photographs of logos underneath the superhydrophobic PDMS trapezoids array and the superhydrophobic PDMS microlens array; (d) A photograph of the PDMS trapezoids sample on one eyeglass lens. Reproduced from [64] with permission; Copyright RSC 2010.

\subsubsection{Reactive Ion Etching}

Recently, Gong et al. [102] demonstrated an efficient method to produce a flexible superhydrophobic PDMS surface with high transparency. Using femtosecond laser processing, they fabricated a stainless steel template, which was comprised of an array of microgrooves with microholes, as shown in Figure 9a. The PDMS solution was poured on the template to make a specific structure comprised of a microwall array with a specific distance between each other, and a microprotrusion at the center of a plate surrounded by microwalls (Figure 9b,c). As shown in Figure 9d,e, excellent transparency and superhydrophobicity were achieved by using the optimized side length of the microwalls and the height of the microcone. The PDMS surface shows superhydrophobicity with a maximum water CA of $154.5^{\circ} \pm 1.7^{\circ}$ and a transparency over $91 \%$, a light loss of less than $1 \%$ compared with flat 
PDMS in the visible range (Figure 9f). Lee et al. [103] reported a three-dimensional hierarchical wrinkled PDMS surface that can exhibit superhydrophobicity even after being repeatedly stretched. They produced these surfaces by molding against polystyrene (PS) templates designed by sequential wrinkling. As shown in Figure 10a, a soft $\mathrm{CF}_{x}$ skin layer was deposited by reactive ion etching (RIE) on the polystyrene wrinkles, which led to PS wrinkles with $\mathrm{CF}_{x}$ layer to enhance the superhydrophobicity. Thereafter, PDMS was cured against the PS master mold to create monolithic PDMS slab with wrinkles. Figure 10b demonstrates that the prepared PDMS slab has almost identical features with that of PS.

(a)
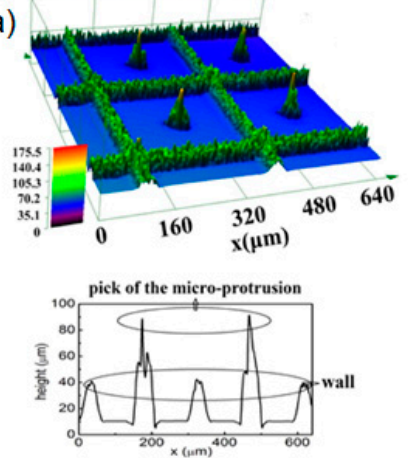

(d)

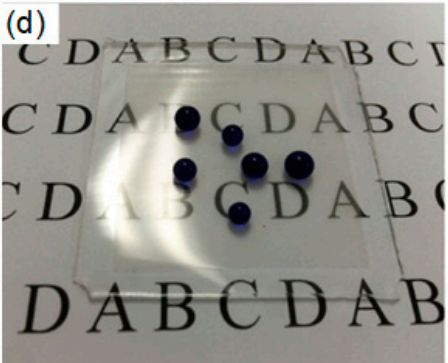

(b)

ฮ

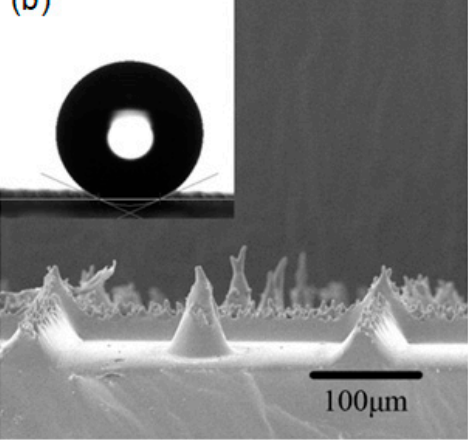

(e)

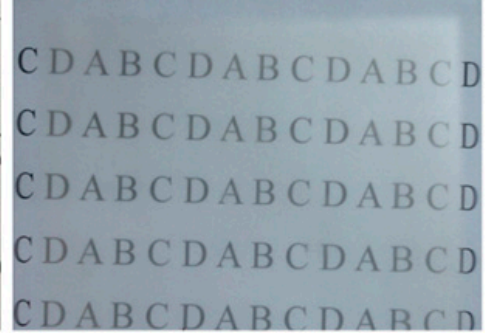

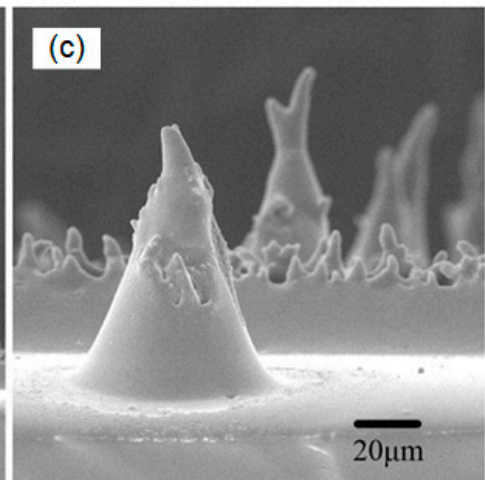

(f)

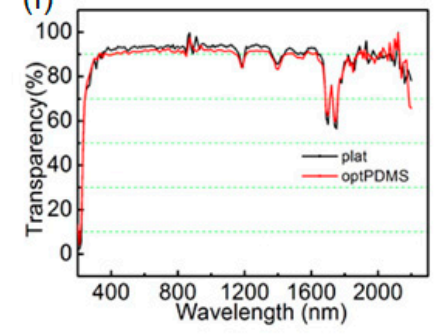

Figure 9. Surface microstructure of PDMS as result of molding into a stainless steel substrate: (a) microscopic data and SEM images under (b) $500 \times$ and (c) $2000 \times$ magnification. The SCA of the thin optimal surface is $154.5^{\circ} \pm 1.7^{\circ}$ and $\mathrm{SA}^{\circ} \pm 0.5^{\circ}$. Optimally-designed PDMS (d) coated on paper and (e) placed at $10 \mathrm{~cm}$ from the paper. (f) Transparency of the optimally-designed surface is over $91 \%$ in the visible light wavelength. Reproduced from [102] with permission; Copyright ACS 2016.

(a)
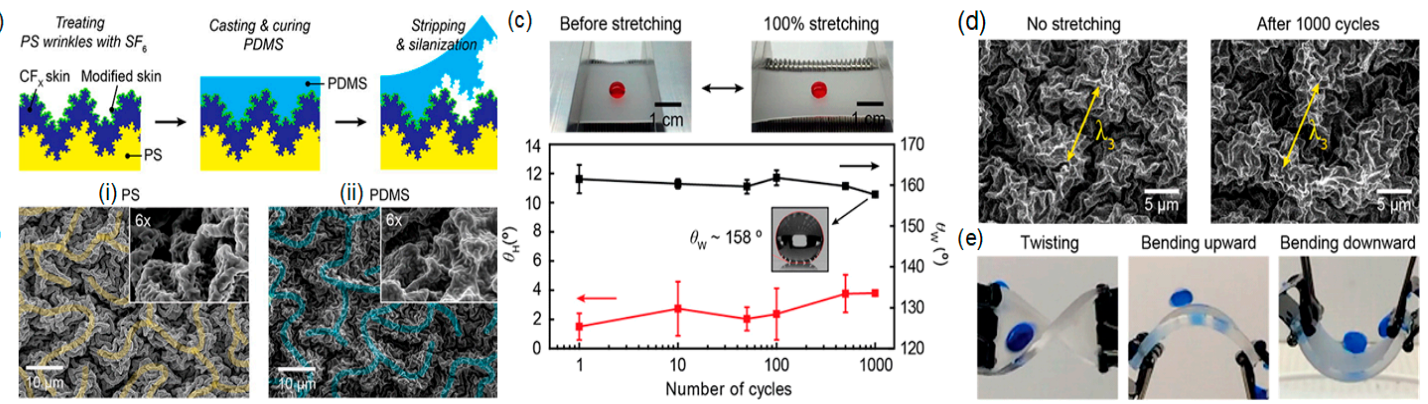

Figure 10. Monolithic formation of 3D hierarchical wrinkles in PDMS: (a) Process of casting PDMS against PS mold; (b) SEM images of hierarchical wrinkles on (i) PS mold and (ii) inverted structures on PDMS; (c) Superhydrophobicity satisfying both $\theta_{\mathrm{W}}>160^{\circ}$ and $\theta_{\mathrm{H}}<3^{\circ}$ was maintained on the 2D PDMS surface even after 1000 stretching cycles; (d) SEM images of surfaces before stretching and after 1000 cycles of stretching; (e) Optical images of water shedding on substrates under twisting, bending, and downward bending. Reproduced from [103] with permission; Copyright ACS 2014. 
To demonstrate the macroscopic effects of monolithic hierarchical wrinkles, the stretchability of the PDMS slab is shown in Figure 10c. Even after 1000 cycles of stretching and releasing, excellent superhydrophobicity with a water contact angle of $150^{\circ}$ was maintained. As shown in Figure 10d, the length of wrinkles increased by only $\sim 11 \mu \mathrm{m}$ even after 1000 cycles. However, this strain does not affect the macroscale water repellency. Furthermore, dynamic water shedding under different mechanical stresses, including multiple times of substrate twisting and bending upward/downward are shown in Figure 10e.

\subsubsection{Hot Pulling Technique}

Similarly, Vullers et al. [104] reported a facile and efficient technique to produce superhydrophobic flexible thin films that are applicable as transparent coatings for optoelectronic devices. They fabricated a thin polymeric nanofur from optical-grade polycarbonate (PC) using a two-step fabrication process, comprised of hot embossing and hot pulling steps, as shown in Figure 11a,b. The thin polymeric nanofur comprised of dense hairs is illustrated in Figure 11c(i), and the cross-section of the thin film is demonstrated in Figure 11c(ii). To examine the self-cleaning properties, the nanofur film was tilted by $30^{\circ}$ and sprinkled with graphite powder. After dropping water onto both plain PC film and the polymeric nanofur film, the water droplets were stuck on the plain PC surface (i.e., no self-cleaning), but they rolled off the nanofur film easily and removed the graphite powder (Figure 11d).

(a) Sacrificial layer bonding

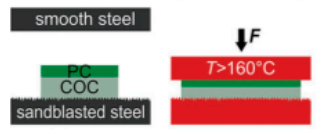

(b) Thin nanofur fabrication
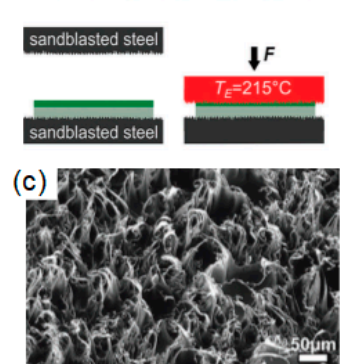

(i)

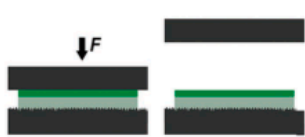

fv
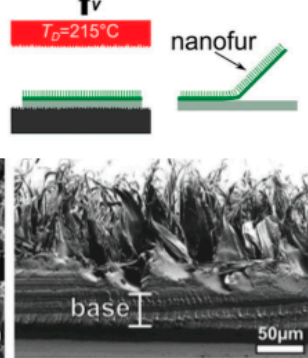

(ii)
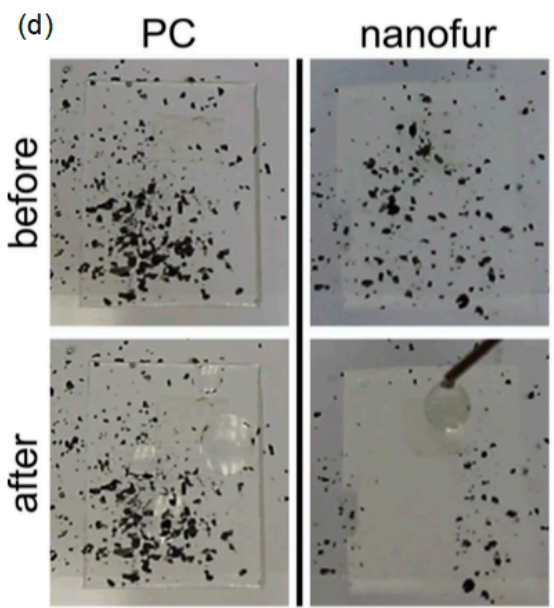

Figure 11. Bioinspired thin nanofur films mimic transparent hairs covering plant leaves. (a,b) Schematic of the fabrication process. PC and COC are bonded together in the hot embossing step. Softened PC fills the cavities of the finely sandblasted top mold pressed into the polymer. Retraction of the mold pulled out the softened PC, creating a crafted surface covered in a dense layer of nano- and micro hairs. The thin nanofur film is then separated from the sacrificial COC layer. (c) SEM images of the thin nanofur film: (i) top view and (ii) cross-section. (d) Self-cleaning of the superhydrophobic thin nanofur film (bottom) in comparison to the unstructured PC film (top). Left: graphite powder was distributed on both surfaces. Right: dispensed water droplets stuck to the unstructured PC film, but rolled down the thin nanofur film, picking up graphite particles and effectively cleaning the surface. Reproduced from [104] with permission; Copyright Wiley 2016.

\subsection{Flexible Nonwettable Transparent Coatings from Assembly of Nanoparticles}

\subsubsection{Flame Spray Pyrolysis}

Despite different techniques, fabricating re-entrant textures on nonflat surfaces has proven extremely challenging. Another important issue limiting the real world impact of superoleophobic surfaces is their complicated fabrication routes and their limited transparency. Hence, Wong et al. [105] presented an approach that enables the rapid, omnidirectional synthesis of flexible, and up to 
99.97\% transparent, superhydrophobic and oleophobic textures on many variable surface types. A three-port burner was used for the flame spray pyrolysis process. A solution mixture of toluene and hexamethyldisiloxane was fed though a custom-built nozzle, and atomized with oxygen gas. The resulting spray was ignited with a premixed methane/oxygen flame. Thereafter, a clean glass slide was placed above the burner. Highly-transparent $\mathrm{SiO}_{2}$ nanoparticles were coated on the glass. Figure 12b shows the schematics of the nanotexture self-assembly approach. A home-built CVD reactor was used to chemically functionalize the silica nanoparticles. For silane deposition, a silica particle-coated glass slide was placed inside the CVD reactor together with $100 \mu \mathrm{L}$ of 1,1,2,2-perfluorooctyl silane. As shown in Figure 12c, upon self-assembly of these $\mathrm{SiO}_{2}$ nanotextures, a superoleophobic surface was easily obtained by vapor silanization of trichloro(1,1,2,2-perfluorooctyl)silane. The transparency of these nanotextures is shown in Figure 12d. Using the deposition time of $15 \mathrm{~s}$, the transparency at $600 \mathrm{~nm}$ reached 100 . When the deposition time was increased to $120 \mathrm{~s}$, a thicker surface resulted in a $13 \%$ loss of transmittance. The fluorosilinization was found to enhance the optical losses by $0.03 \%$ and $6 \%$ for aerosol deposition time of 15 and $120 \mathrm{~s}$, respectively. These superolephobic textures were applied to a variety of uneven profiles, such as the inner side of a bowl-shaped crucible, the inner walls of a closed-end tube, and a much thinner glass tube with an aspect ratio of 15 . Successfully nanotexturing of the latter was indicated by balling up of the introduced oil in the Cassie-Baxter state. We concluded that the present method brings a significant advance in imparting transparency and superamphiphobicity to an inapplicable family of materials and geometries for multifunctional applications (Figure 12e,f).

(a)

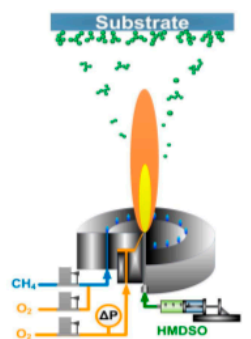

(d)

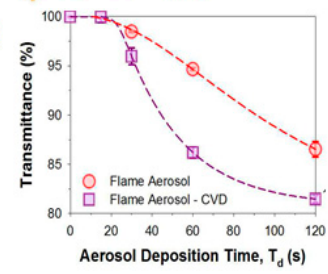

(b)

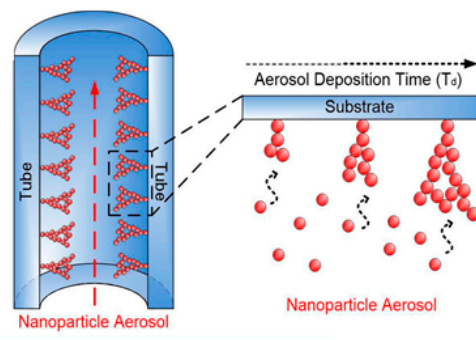

(e)

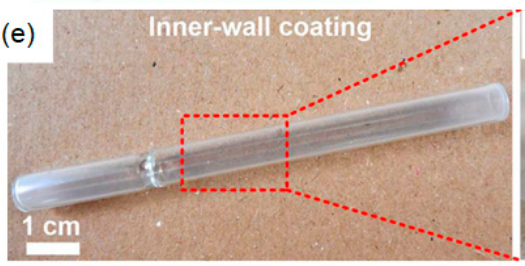

(c)

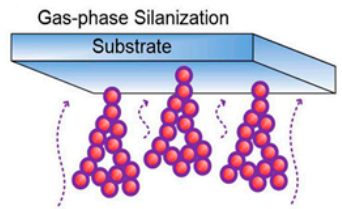

Trichloro(1H,1H,2H,2H-perfluorooctyl)silane

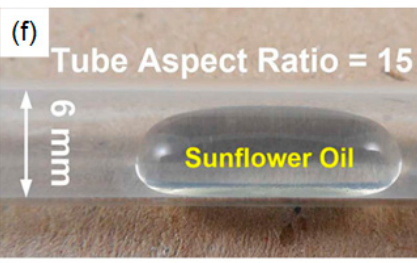

Figure 12. Self-assembly of omnidirectional re-entrant textures: (a) Experimental schematics of the facile two-step synthesis of superoleophobic coatings using flame aerosol; (b) Schematic description of the superoleophobic nano textures fabricated by omnidirectional deposition of nanoparticle aerosols; and (c) fluorosilanization by APCVD (atmospheric pressure chemical vapor deposition). (d) UV-Vis transmittance profile of superolephobic textures at $600 \mathrm{~nm}$, reaching up to $99.97 \%$ at a deposition time of $15 \mathrm{~s}$. Application of omnidirectional nanotexturing for (e) inner walls of high-aspect-ratio glass tubes with a diameter of $6 \mathrm{~mm}$ and length of $90 \mathrm{~mm}$. (f) Sunflower oil droplet introduced into the tube showed balled up Cassie-Baxter state. Reproduced from [105] with permission; Copyright Wiley 2017.

\subsubsection{Photolithography}

Alternatively, another concept was demonstrated to develop transparent superomniphobic surfaces, which have a range of applications such as coatings for windows, phones, tablets, and computer screens. Golovin et al. [106] have reported a facile method to create flexible and highly-transparent superomniphobic surfaces that can repel a range of liquids with low or high surface tension. A simple cost-effective spray method on master-molded PDMS pillars was used for these surfaces. As shown in Figure 13a, the synthesis method is comprised of photolithography and spraying. 
Using photolithography, uniform square arrays of holes were fabricated on a silicon master mold. Initially, a thick layer of photoresist was spin-coated on a silicon wafer, and baked for $90 \mathrm{~s}$ at $115^{\circ} \mathrm{C}$. The layout of the micropattern was defined by exposure to $365 \mathrm{~nm}$ UV light. Then, inductively-coupled plasma reactive ion etching was used to develop 20- $\mu \mathrm{m}$ and $40-\mu \mathrm{m}$ deep micropore arrays in the exposed region. A PDMS mixture was poured over Si masks at room temperature. The mixture was degassed and subsequently cured for $3 \mathrm{~h}$ at $80{ }^{\circ} \mathrm{C}$. Then, the PDMS was removed from the mask, leaving square arrays of pillars. Thereafter, a solution mixture of 1,1,2,2-hepadecafluorodecyl polyhedral oligomeric silsesquioxane (F-POSS) and PDMS was prepared and sprayed on the PDMS pillars. Spraying polymers with low surface energy can result in controllable reentrant texture with oleophobic characteristics. During the fabrication process, molds were prepared with $D^{*}$ values ranging from 10 to 100 . ( $D^{*}$ is a measure of the solid-liquid interfacial area: $D^{*}=((R+D) / R)^{2}$. $2 R$ is the diameter of the texture, and $2 D$ is the inter-feature spacing). The modified Cassie-Baxter relationship can be rewritten in terms of $D^{*}$ :

$$
\cos \theta^{*}=-1+\frac{1}{D^{*}}\left[\frac{\pi}{2 \sqrt{3}}(1+\cos \theta)\right]^{2}
$$

where $\theta$ is the Young's contact angle and $\theta^{*}$ is the Cassie-Baxter contact angle. SEM micrographs of the PDMS pillar surface $\left(D^{*}=10\right)$ coated with PDMS/F-POSS for various spray times $(30,120$, and $240 \mathrm{~s})$ are demonstrated in Figure 13b, while those at $D^{*}=100$ and spraying times of 30,120, and $180 \mathrm{~s}$ are demonstrated in Figure 13c.

(a)

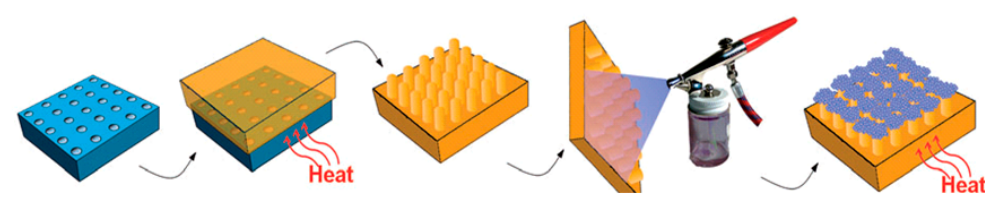

(b)

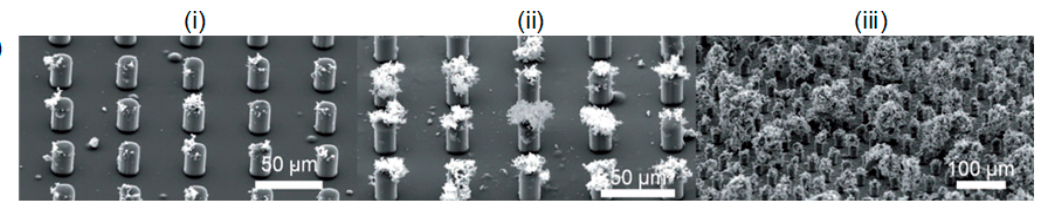

(c)

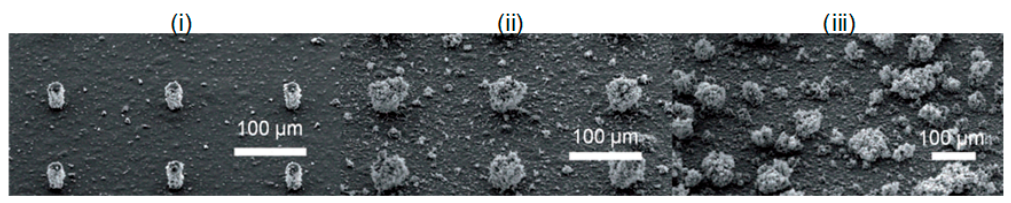

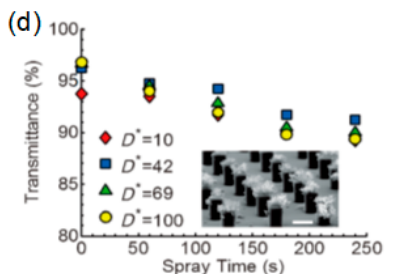
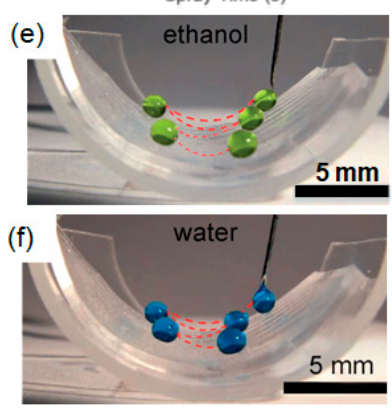

Figure 13. (a) Fabrication method. First the desired pattern was etched into a silicon master mold using photolithography. PDMS was poured into the master mold and cured in an oven. PDMS/F-POSS was sprayed onto the pillars, which were subsequently cured again. (b) FESEM images of PDMS pillars $\left(D^{*}=10\right)$ spray coated with PDMS/F-POSS for (i) 30, (ii) 120, and (iii) $240 \mathrm{~s}$. (c) PDMS pillars with $D^{*}=100$ spray coated for (i) 30 , (ii) 120 , and (iii)180 s. (d) Transparency of the surfaces coated with the PDMS/F-POSS spray for different spray times and $D^{*}$ values. $(\mathbf{e}, \mathbf{f})$ Superimposed movie frames taken at 10-ms intervals for droplets of water and ethanol, respectively. The droplets rolled back and forth several times before reaching the edge of the substrate, which highlights the ultra-low CAH. Reproduced from [106] with permission; Copyright Wiley 2013.

It is clearly seen that pillars fabricated using this spray coating-based method introduce both re-entrant curvature and hierarchical textures, and the resulting surface repels both water and low-surface-tension liquids. The effects of spray time and $D^{*}$ on the transparency of the fabricated surfaces are illustrated in Figure 13d. As the fraction of the pillars per unit area decreases (increasing 
$D^{*}$ ), the transmittance decreases. Similarly, the fabricated surfaces with $D^{*}=100$ (sprayed for $120 \mathrm{~s}$ ) were curved into arcs, and various liquid droplets with high or low surface tension were placed on them (Figure 13e,f). The droplets rolled back and forth along the length of the surface, until the edge was reached. The trajectories of both water and ethanol droplets are shown in the superimposed frames at 10-ms intervals. This indicates that this process for preparing transparent, flexible, and superomniphobic surfaces is one of the best suited for scaling up to functionalize significantly larger areas.

\subsubsection{Sol-Gel Technique and Spray Coating}

Superhydrophobic self-cleaning coatings have attracted significant attention from both the scientific community and industrial world. However, their real-world applications are still restricted by their low transparency, poor durability, and expensive toxic reagents and complex preparation processes. Li et al. [107] developed a versatile and efficient method to fabricate environmentally-safe and self-cleaning coatings, based on the self-assembly of modified porous chain-like $\mathrm{SiO}_{2}$ nanoparticles. The synthesis of silica/solution and its spray coating process are illustrated in Figure 14a. The adhesion of the coatings was also demonstrated. As shown in Figure 14b, a water droplet at the syringe trip can be squeezed to contact the coating, and picked off the surface several times without leaving any water residue on the superhydrophobic paper surface, which suggests the low adhesive force of the coatings. In practical applications, the performance of the transparent self-cleaning coatings towards common liquid contaminants (including muddy water, coffee, and juice) should be investigated. As shown in Figure 14c, the superhydrophobic paper demonstrates excellent liquid repellency, as proven by the easy rolling off of muddy water, coffee, and orange juice on its surface. After applying on a fabric (Figure 14d), the material also showed good antifouling ability towards the same contaminants, while the original fabric was seriously soiled. Similar antifouling properties was also investigated for coating shoes, as shown in Figure 14e. Such self-cleaning and antifouling performance to dust and common liquids would satisfy the requirements of real-life applications. Similarly, Gao et al. [108] fabricated a transparent and UV-resistant superhydrophobic array of $\mathrm{SiO}_{2}$-coated $\mathrm{ZnO}$ nanorods, which were prepared on a thin sheet of PET film.
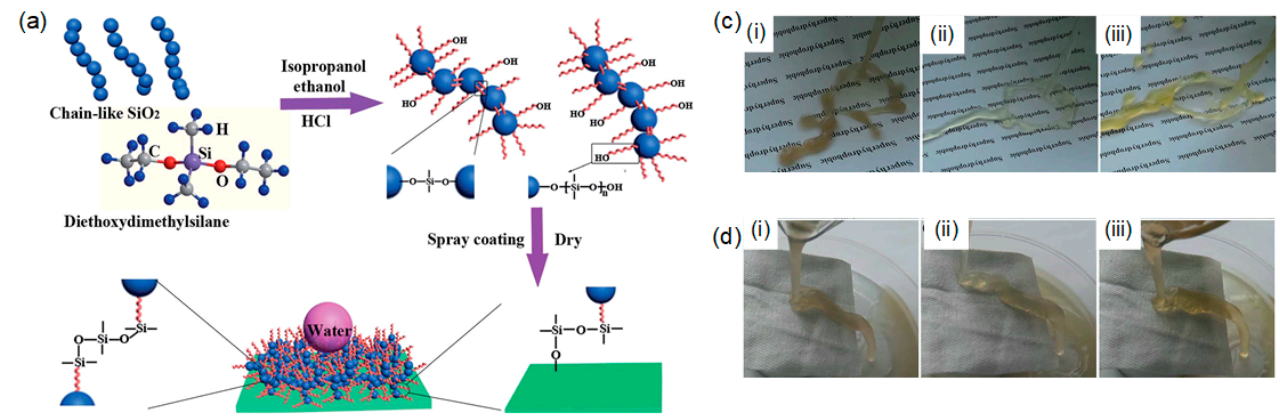

(b)
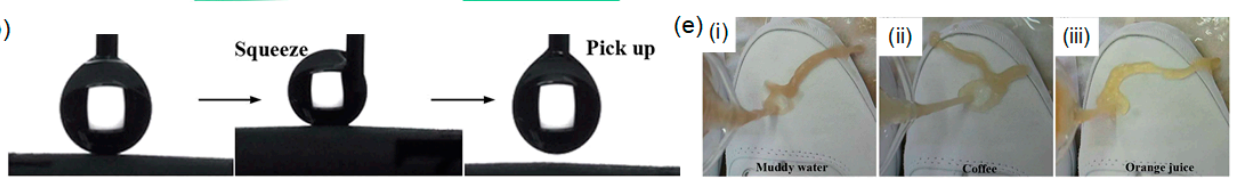

Figure 14. (a) Schematic illustration of the fabrication of environmentally safe and transparent superhydrophobic coatings on various substrates via the nanoparticle self-assembly method. (b) The dropping, squeezing, and picking up of a water droplet, showing the low adhesive force on superhydrophobic paper. Three common liquid contaminants ((i) muddy water, (ii) coffee, and (iii) orange juice) were poured on prepared superhydrophobic coatings on (c) paper, (d) fabric, and (e) a shoe surface, to test the antifouling ability of the coating. Reproduced from [107] with permission; Copyright RSC 2014. 


\subsection{Flexible Nonwettable Transparent Coatings Using Thiol-Ene Reaction}

For a broad range of applications, the ability to create robust superhydrophobic surfaces that can stably trap micropockets of air beneath the water drop to maintain the Cassie state and exhibit extreme water repellency behavior is of great importance. Introducing micro/nanostructures to obtain surface roughness is the prerequisite for super hydrophobicity. However, major challenges remain in developing scalable methodologies for fabricating such superhydrophobic surfaces that also demonstrate optical transparency, mechanical stability, and stretchability. Wang et al. [109] developed a new type of superhydrophobic surface, in which the key layer composed of three-dimensional silica nanostructures is replicated from a hydrogel template. The coating exhibits strong water repellency, optical transparency, and mechanical robustness even after 500 cycles of mechanical stretching at $100 \%$ strain. In addition to surface roughening, nonflourinated hydrophobic surfaces are of interest for their reduced cost, toxicity, and environmental impact. Raquel et al. [110] developed polymer-based composite coatings on PMMA substrate that demonstrate water repellency, flexibility, optical transparency, and mechanical stability.

Many efforts have been made to replace glass and plastic films with sustainable materials with competitive strength, thermal expansion coefficients, transparency, and heat resistance. Films and nanopapers prepared from nanofibrillated cellulose (NFC) are ideal alternatives, since they are mechanically strong, lightweight, transparent, non-toxic, and biocompatible. Taking the above advantages into account, NFC films have been considered in recent years for use in electronic devices including displays, transistors, organic light emitting diodes, touch screens, lithium ion batteries, solar cells, transparent conductive electrodes, and antennas. Thus, there is a corresponding need to find fabrication methods that could tailor properties of the NFC films to generate additional functionality and improve their applicability. Hence, Guo et al. [111] reported a novel and facile process to functionalize the patterns and tailor the wetting properties of NFC films. The process is comprised of the deposition of nanosilicone filaments using in situ polycondensation of trichlorovinylsilane (TCVS), with further functionalization using the thiol-ene reaction. The prepared slippery, lubricant-infused NFC films repelled both water and organic liquids. The detailed fabrication process is schematically illustrated in Figure 15a. The NFC films modified with the TCVS-silicone nanofilaments (SNFs) were placed on a glass slide, wetted with 1,1,2,2-perflurodecanethiol solution in ethyl acetate, and covered with a photo mask. The covered NFC film was immediately cured with UV light with a wavelength of $260 \mathrm{~nm}$ for 5 min to prepare superhydrophilic areas. The NFC film was redeposited on a glass slide and covered with a quartz slide after addition of $100 \mu \mathrm{L}$ of cystemine hydrochloride. After 1 min exposure to UV light, the NFC film was completely rinsed with ethanol and dried with a nitrogen flow. The prepared NFC film carrying the hydrophobic-hydrophilic patterns was kept in a room temperature environment. Similarly, NFC films containing TCVS-SNFs were reacted with 1,1,2,2-perflurodecanethiol solution under UV light with a wavelength of $260 \mathrm{~nm}$ for $5 \mathrm{~min}$. After a proper cleaning process and drying with nitrogen gas, the film was impregnated by spreading $20 \mu \mathrm{L} \cdot \mathrm{cm}^{-2}$ lubricant fluid (Krytox 103) and kept for $2 \mathrm{~h}$ to ensure spontaneous, complete wicking throughout the capillary structures of the films. Thereafter, the NFC film was positioned vertically overnight to drain excess lubricant. As shown in Figure 15b, the SEM image of the NFC film shows TCVS SNFs. Figure 15c shows the $20-\mu \mathrm{m}$ NFC film that is flexible, translucent, strong, and easy to handle. The wettability of the superhydrophobic/superhydrophilic NFC films created via thiol-ene click reaction was demonstrated in Figure 15d. The static contact angle of bare NFC film is $33^{\circ}$, confirming the hydrophilic characteristic of cellulose, which comprises of hydroxyl group and oxygen-containing groups. The surface with TCVS-SNFs, in contrast, shows a micro/nanostructured layer with a static contact angle of $123^{\circ}$. 
(a)
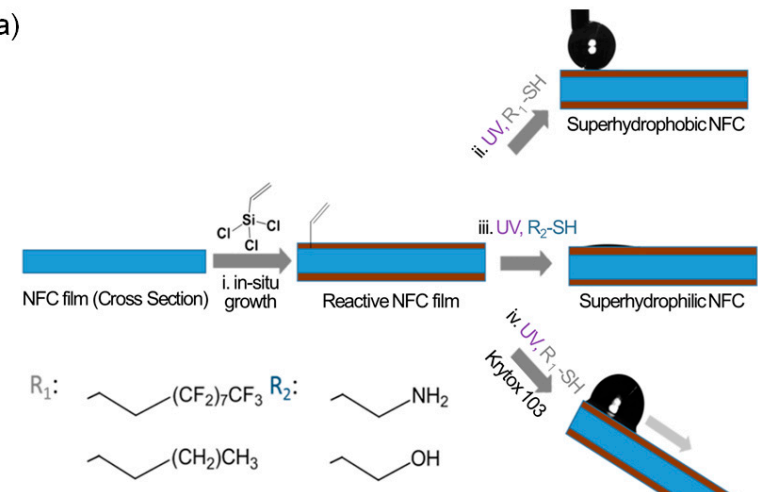

(b)
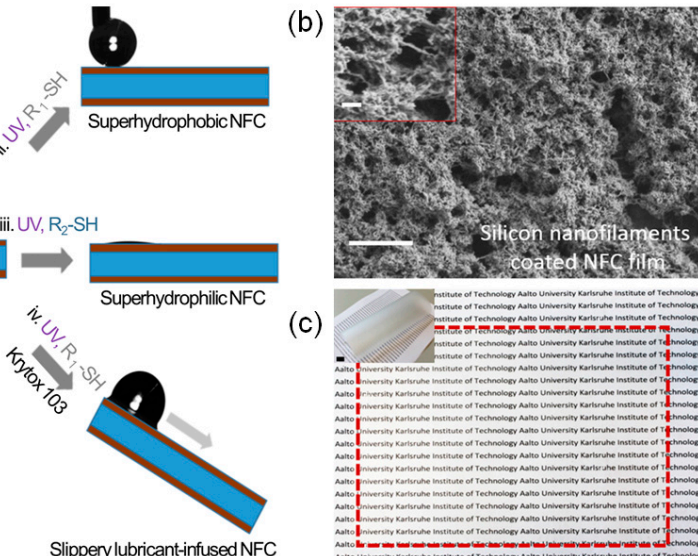

(c)

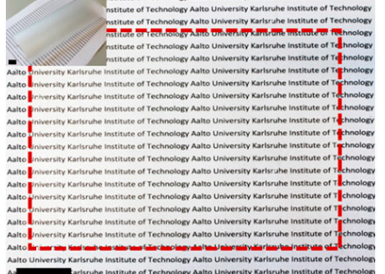

(d)

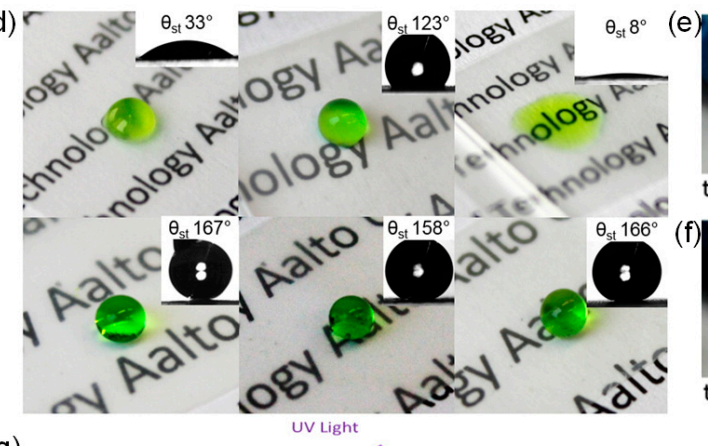

(g)
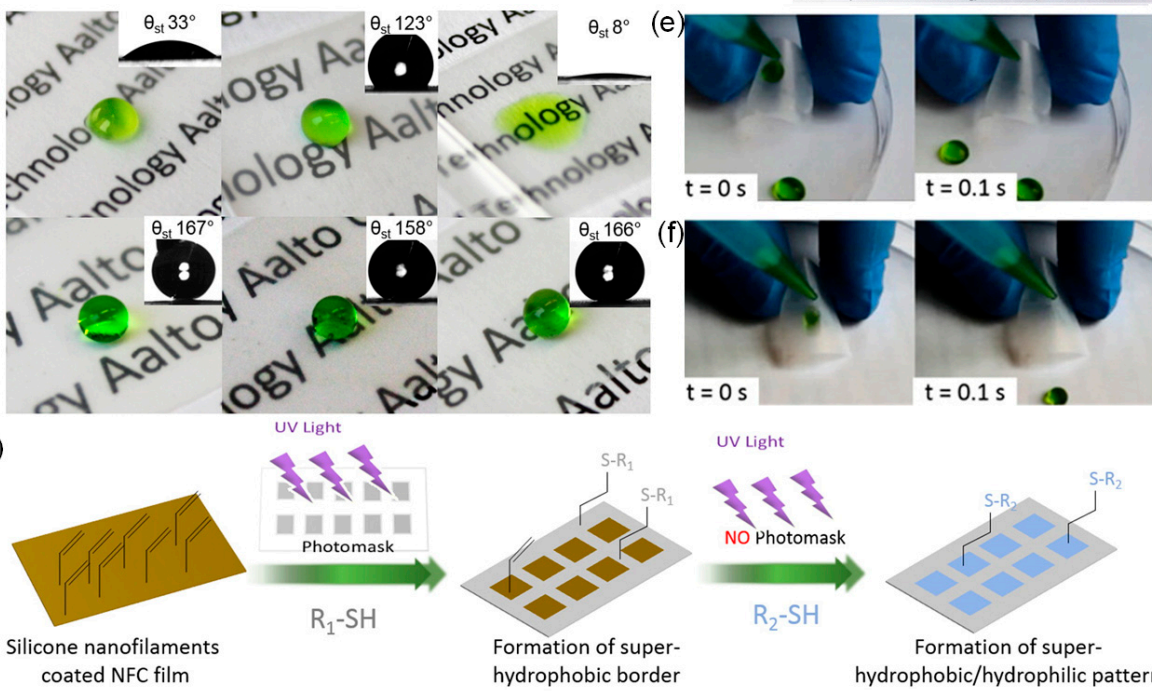

uv Light

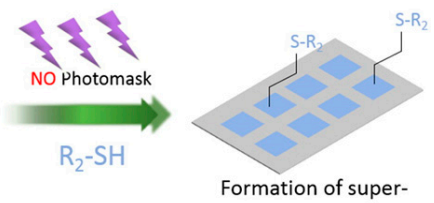

hydrophobic/hydrophilic pattern

Figure 15. (a) Schematic illustration of the functionalization of films of nano-fibrillated cellulose (NFC): (i) The NFC film surface was used as a substrate for growing silicone filaments (SNFs) carrying reactive vinyl groups (TCVS-SNFs); (ii,iii) The vinyl groups can be reacted with thiolated compounds via photoinduced thiol-ene click reaction. For instance, the reactions can introduce hydrophobic or hydrophilic groups to impart superhydrophobicity or superhydrophilicity, respectively; (iv) Slippery liquid-infused porous NFC film surfaces (SLI-NFC) can be fabricated by impregnation of porous NFC films that have been fluorinated by the thiol-ene reaction with a lubricant that is both low in surface energy and chemically inert. (b) SEM image revealing the surface topography of an NFC film after growing TCVS-SNFs on the surface. (c) A photograph of a printed A4 paper sheet covered with an NFC film to illustrate its transparency and flexibility (inset). (d) Dyed water droplets deposited on the surface of NFC films with different modifications. Upper frames from left to right: NFC film, NFC film covered with reactive TCVS-silicone nanofilaments, and hydrophilic NFC film with cystemine functionalization. Lower frame from left to right: fluorinated NFC film, fluorinated NFC film (back side), and alkylated NFC film. (e) Bent NFC films. (f) Schematic illustration of the formation of superhydrophobic-superhydrophilic patterns on a TCVS-NFXC film by the thiol-ene reaction. Reproduced from [111] with permission; Copyright Wiley 2016.

Functionalization of the reactive TCVS-NFC film with hydrophilic cystemine or 2-mercaptoethanol decreased CA (contact angle) from $123^{\circ}$ to $8^{\circ}$ in both cases. To develop superhydrophobic NFC films with TCVS-SNFs, the NFC was modified with various alkylthios via thiol-ene reaction. Thus, functionalization of the reactive TCVS-NFC film with hydrophobic 1-butanthiol or 1,1,2,2-perfluorodecanethiol demonstrates the surface with a CA of $166^{\circ}$ and $167^{\circ}$, respectively. However, both sides of the film had a $\mathrm{CA}>158^{\circ}$ with a $\mathrm{CAH}<3^{\circ}$. To further investigate the 
transparency and mechanical stability of the NFC films, Levkin's group has demonstrated the superhydrophobicity of bent TCVS-NFC films (Figure 15e). The functionalized TCVS-NFC films could withstand 100 cycles of bending and abrasion with a $10 \mathrm{~g}$ load, with no apparent change in the superhydrophobic character. In addition to the mechanical durability, further development of patterned surface on modified NFC films is also demonstrated in Figure 15f. In the first step, a reactive NFC film was wetted with an ethyl acetate solution of 1,1,2,2-perflurodecanethiol and further exposed to UV light through a photo mask.

This led to the formation of both superhydrophobic channels. After proper washing, the whole surface was further subjected to a second round of the thiol-ene reaction with hydrophilic cystemine. This treatment functionalized the reactive vinyl areas, which led to the creation of superhydrophobicsuperhydrophilic patterns on the NFC films. This approach allowed the fabrication of NFC films with patterned superhydrophobic-superhydrophilic domains that can be used for bio-applications.

\section{Applications of Transparent and Flexible Superamphiphobic Surfaces}

The practical application of transparent and flexible superhydrophobic surfaces is the ultimate purpose of all related studies, whether they are about the theory, materials, and/or fabrication. A number of fabrication methods have been discussed in the previous section. Now, we summarize the applications of such surfaces. Transparent superhydrophobic nanocoatings have extensive applications in windows, eyeglasses, camera lenses, and solar cell systems [112,113]. In general, transparency will be reduced as the surface becomes rougher because of light scattering. However, it has been suggested that the optimization of surface roughness is an important factor for creating a superhydrophobic surface. Thus, both properties need to be balanced for industrial applications. It is reported that a silica nanoparticle-based nanocoating provides excellent optical properties, is convenient for further chemical treatment, and the coating thickness and roughness can be easily controlled. Due to these advantages, silica-based materials have received a great deal of attention in this research field. In general, reflecting light on a transparent surface causes two problems: energy loss and imaging interference [114]. Nowadays, antireflection is necessary in daily life. Thus, based on these perceptions, an extensive number of micro-nanostructured surfaces have been fabricated [115-119]. Combining transparency and flexibility, Tsui et al. [65] fabricated a PDMS nanocone film for photovoltaic solar cell applications. Similarly, focusing on solar application, Kong et al. [66] also fabricated a thin film that is optically transparent and, therefore, could be used for solar cell applications, windows, or mobile screes, etc. Combined with transparency and antireflection properties, Toma et al. $[80,81]$ demonstrated the flexible and transparent superhydrophobic film which saves energy by recovering energy efficiency process. With an aim on transparent, flexible, and self-cleaning properties, superhydrophobic surfaces have also been developed for eyeglasses and sunglasses. Possessing the properties of self-cleaning and optical transparency, a thin, flexible polymeric film could be applied for light management applications and it is attractive for commercial applications in optoelectronic devices [104]. Highly-flexible superhydrophobic thin film can be used for closed-end tubes and several uneven complex geometries [105]. Similarly, displaying excellent self-cleaning and good flexibility characteristics, some polymeric films can be used for mobile phone screens [106]. A few transparent coatings have also been economically and efficiently applied on various substrates, such as glasses, paper, shoes, plastics, walls, and metals, enhancing the antifouling performance and allowing rapid repair [107]. Other applications of flexible superhydrophobic surfaces have also been reported in the past few years. The fabrication of superhydrophobic-superhydrophilic patterns on flexible and transparent superhydrophobic coatings expands the potential applications to other areas, such as bio-sensing, biomedical, biotechnological, and diagnostics fields [111]. Similarly, Fukuda et al. [120] developed highly-transparent superoleophobic polyester stripes coated with silica nanoparticles using a spraying method. The $\mathrm{SiO}_{2}$ nanoparticles on each stripe enhanced the microscale surface roughness and repelled various oils. The polyester stripes were used to provide antifouling properties on solar cells application, which demonstrates antifouling properties. 
Currently, fabrication methods for the development of flexible and transparent superamphiphobic surfaces have become particularly desirable. Their self-cleaning and water resistanr properties prevent bacterial growth and, therefore, a robust and stable means to prevent bacterial growth is possible. Freschauf et al. [121] presented a rapid fabrication method for creating superhydrophobic surfaces which is stable, flexible, and demonstrates an antibacterial property. Their fabrication method involves a purely structural modification free of chemical additives and illustrates the prevention of Gram-negative Escherichia coli (E. coli) bacterial growth on different substrates, such as PS, PC, and polyethylene (PE), etc. Future research on flexible and transparent superamphiphobic surface are not only driven by its automotive and construction applications, but also further research is required to explore possibilities for aircraft components, rural areas, and biomedical applications. However, more research should be carried out in order to recognize possible ways of improving the self-healing ability of surfaces and materials before they are adapted by industry with respect to major changes in materials properties and their subsequent potential future applications in several composite-based industries. Despite all of these achievements, many challenges are still active and several improvements should all made before such surfaces are used in applications, such as desalination, aerosol filtration, and anti-icing.

\section{Recommendations and Future Directions for Flexible Transparent Superhydrophobic Surfaces}

Over the last ten years, the number of publications on the development of transparent, flexible, and superhydrophobic surfaces has increased exponentially. Various techniques have been demonstrated to produce flexible and transparent materials with self-sustained topographies that can repel water. Despite the substantial scientific progress, however, currently no single surface has adequate resistance against mechanical wear required by industrial standards and commercialization. This review presents what has been developed during the last 10-15 years in terms of flexible and transparent superhydrophobic surfaces. There is a wide range of reports and claims of durable transparent superhydrophobic surfaces. However, researchers working on the applications of transparent water-repellent coatings still do not have a unified and standardized procedure of the fabrication process, or in reporting the flexibility of their materials. Flexibility tests should be conducted similar to ASTM standards developed for industrial coatings. At the same time, more research is needed to further improve the mechanical durability characteristics of such transparent coatings. The present review reveals that some reported techniques are well-suited for specific applications, and this allows specific recommendations. A coating should have good substrate adhesion for large-scale applications [122,123]. In addition to adhesion, abrasion testing should be employed to test the stability of the surfaces for outdoor applications. Some tests, including the laundry test, should be considered for textiles, pencil hardness, or blade testing for surfaces that will come into contact with sharp objects for aerospace applications.

Until now, the existing background knowledge of fabrication methods for the development of flexible and transparent superamphiphobic surfaces proved very helpful to society. Three different fabrication techniques have been developed for flexible and transparent superamphiphobic surfaces to repel water, oil, and surfactant-containing liquids. All three techniques result in surfaces that are extremely repellent to water and hexadecane. The fabrication of the re-entrant geometry of the protrusions that are responsible for the superoleophobicity is a most promising method. The various etching methods that allow a good control of the structure-size parameters can be used for further theoretical investigation. Our discussed examples in this review have hopefully shown that many structural types are possible. This review revealed that flexibility and transparent superoleophobic properties can be attained using many kinds of structures. In fact, many inorganic and organic materials' surfaces can be converted to superoleophobic surfaces. This, in turn, opens up a wide range of potential applications. The high contact angles and low tilt angles for the pattern transfer, layer-by-layer, and thio-ene reaction techniques result in self-cleaning and anti-smudge properties. In addition, all techniques demonstrate some repellence toward surfactant-containing liquids. The pattern transfer 
method performs well for repellent surfaces because these surfaces repel very low surface tension liquids along with properties of mechanical durability. The nanoparticle assembly techniques have the greatest flexibility in terms of substrate applicability and modifying the functionality for various applications. The substrate independence can be advantageous for applications where multiple base materials are frequently used or where the same properties are sought across different products. Jiang et al. [124] investigated different types of mechanical durability tests, including tape peeling, bending, rotary abrasion, and dynamic impact on flat and structured surfaces. The surface durability was evaluated by changes in wetting performance.

Typically, superhydrophobic coatings are fabricated using fluorocarbon materials, which possess low surface energy $[125,126]$. However, long-chain fluorocarbon materials, which can decompose into perfluorooctanoic acids, have been classified as emerging contaminants by the U.S. Environmental Protection Agency [127,128]. Similarly, the U.S. Environmental Protection Agency (EPA) classifies long-chain fluorocarbon materials as "emerging contaminants" because of their potential decomposition into perfluorooctanoic acid (PFOA), which is considered persistent, bioaccumulative, and potentially toxic to humans [129]. Therefore, superhydrophobic coatings fabricated using fluorocarbon materials are not ideal for direct food contact applications. Further, the use of coatings in food-related applications is regulated by the U.S. Food and Drug Administration (FDA). To make a superhydrophobic coating for a food container, the materials in the coating should be nontoxic and classified as safe for direct food contact by the FDA [130]. In addition to environmental pollution, significantly high cost is an important barrier for the wide commercial applications of these materials. Therefore, developing scalable superhydrophobic coatings with fluorine-free materials is of great interest in both academic and industrial areas. Similarly, textile substrates are conventionally finished with fluorocarbons in a wet chemical process by padding, followed by thermal stabilization, for both water and oil repellence. While the achieved performances of these conventional concepts are already rather good, disadvantages have to be considered as well. These refer to limited wash stability, abrasion resistance, and wastewater and environmental issues associated with the use of long-chain (C8) fluorocarbons based on perflurooctanoic acid (PFOA) derivatives in the finishing step that are known to be bio-persistent. Therefore, recent developments in the field of wet chemical finishing processes should have concentrated on the developments of innovative short-chain fluorocarbons and/or stabilizing processes in order to increase the wash fastness of the finish.

\section{Conclusions and Outlook}

In this review, we have discussed the state of the art in the fabrication methodologies of transparent superhydrophobic and superoleophobic coatings, and demonstrated the resistance to bending and folding while maintaining nonwetting characteristics. Though superhydrophobicity and nanotechnology are both recently-developed concepts, they have already become essential to a great deal of research and also have potential for large-scale applications. The combination of both has inspired people to fabricate multifunctional superhydrophobic surfaces for many applications. The application and special examples of flexible and transparent superamphiphobic surfaces have been discussed. Although remarkable accomplishments have been achieved in this field during the past decades, it should be pointed out that there still remain many challenges and problems to be solved for further study. There has been significant progress, both theoretically and experimentally, in creating superhydrophobic surfaces. The study of flexible superhydrophobic surfaces with high transmittance, however, is relatively new. For high transmittance in the visible wavelength region, researchers encountered some additional challenges in creating superhydrophobicity, such as (a) the roughness level of the surface and (b) keeping the refractive index low. A review of recent literature reports that most of the published works have not demonstrated any performance results related to flexibility or stretchability against outdoor applications. A few reports on transparent superamphiphobic surfaces also exist, which showed excellent outdoor applications and substrate-independent universal fabrication methods, but with no wear resistance or flexibility characterization. Furthermore, 
some environmentally-friendly coatings have been proposed to exhibit excellent thermal stability and dynamic/thermoresponsive oleophobicity.

We have presented three key fabrication processes, namely, the pattern transfer method, nanoparticle assembly process, and thio-ene reaction process, which are suitable for solar energy conversion devices and biosensors. Among various techniques, self-assembly techniques are simple and versatile. They can be obtained by dip coating, spray coating, and spin coating; and their surface chemistry can be altered via CVD to minimize surface energy to balance the forces in colloidal systems (which adjust the coating morphology and uniformity). The following are the respective advantages of different materials in the field of artificial superhydrophobic nanocoatings: Carbon-based and silica-based coatings generally have excellent chemical resistance, however, the disadvantages of various materials should be noted. For example, the problem of metallic oxide corrosion, the high cost of carbon nanotubes and graphene, and the toxicity of organic polymers. Nowadays, researchers should focus on solving these problems. Furthermore, a theoretical model is still needed, because classical models, such as Wenzel and Cassie models, are only appropriate for special conditions.

As summarized above, combining transparency and flexibility is very challenging, and it is not demonstrated frequently. However, in the past few years, there has been considerable progress towards achieving both in a single-layer coating. It is also noted that most of these techniques should be developed for wider applications. With an ever-increasing number of scientists focusing on this area, we believe there is an exciting future in the theory, synthesis, and commercialization of superhydrophobic nanocoatings.

Acknowledgments: This work was supported by the Priority Research Centers Program (grant 2009-0093823) through the National Research Foundation of Korea (NRF) funded by the Ministry of Education, Science, and Technology (MEST). This work was also supported by KIST project (2E27930).

Conflicts of Interest: The authors declare no conflict of interest.

\section{References}

1. Barthlott, W.; Neinhuis, C. Purity of the sacred lotus, or escape from contamination in biological surfaces. Planta 1997, 202, 1-8. [CrossRef]

2. Koch, K.; Bohn, H.F.; Barthlott, W. Hierarchically sculptured plant surfaces and super hydrophobicity. Langmuir 2009, 25, 14116-14120. [CrossRef] [PubMed]

3. Feng, X.-Q.; Gao, X.; Wu, Z.; Jiang, L.; Zheng, Q.-S. Superior water repellency of water strider legs with hierarchical structures: Experiments and analysis. Langmuir 2007, 23, 4892-4896. [CrossRef] [PubMed]

4. Sun, T.; Feng, L.; Gao, X.; Jiang, L. Bioinspired surfaces with special wettability. Acc. Chem. Res. 2005, 38, 644-652. [CrossRef] [PubMed]

5. Zheng, Y.; Gao, X.; Jiang, L. Directional adhesion of superhydrophobic butterfly wings. Soft Matter 2007, 3, 178-182. [CrossRef]

6. Gao, X.; Jiang, L. Biophysics: Water-repellent legs of water striders. Nature 2004, 432, 36. [CrossRef] [PubMed]

7. Bormashenko, E.; Bormashenko, Y.; Stein, T.; Whyman, G.; Bormashenko, E. Why do pigeon feathers repel water? Hydrophobicity of pennae, Cassie-Baxter wetting hypothesis and Cassie-Wenzel capillarity-induced wetting transition. J. Colloid Interface Sci. 2007, 311, 212-216. [CrossRef] [PubMed]

8. Blossey, R. Self-cleaning surfaces-Virtual realities. Nat. Mater. 2003, 2, 301-306. [CrossRef] [PubMed]

9. Quéré, D.; Reyssat, M. Non-adhesive lotus and other hydrophobic materials. Philos. Trans. R. Soc. A 2008, 366, 1539-1556. [CrossRef] [PubMed]

10. Bhushan, B. Biomimetics: Bioinspired Hierarchical-Structured Surfaces for Green Science and Technology, 2nd ed.; Springer International: Cham, Switzerland, 2016.

11. Shin, S.; Seo, J.; Han, H.; Kang, S.; Kim, H.; Lee, T. Bio-Inspired Extreme Wetting Surfaces for Biomedical Applications. Materials 2016, 9, 116. [CrossRef] [PubMed]

12. Gogolides, E.; Ellinas, K.; Tserepi, A. Hierarchical micro and nano structured, hydrophilic, Superhydrophobic and superoleophobic surfaces incorporated in microfluidics, microarrays and lab on chip microsystems. Microelectron. Eng. 2015, 132, 135-155. [CrossRef] 
13. Martin, S.; Brown, P.S.; Bhushan, B. Fabrication techniques for bioinspired, mechanically-durable, superliquiphobic surfaces for water, oil, and surfactant repellency. Adv. Colloid Interface Sci. 2017, 241, 1-23. [CrossRef] [PubMed]

14. Ellinas, K.; Tsougeni, K.; Petrou, P.S.; Boulousis, G.; Tsoukleris, D.; Pavlatou, E.; Tserepi, A.; Kakabakos, S.E.; Gogolides, E. Three-dimensional plasma micro-nanotextured cyclo-olefin-polymer surfaces for biomolecule immobilization and environmentally stable superhydrophobic and superoleophobic behavior. Chem. Eng. J. 2016, 300, 394-403. [CrossRef]

15. Kontziampasis, D.; Boulousis, G.; Smyrnakis, A.; Ellinas, K.; Tserepi, A.; Gogolides, E. Biomimetic, antireflective, superhydrophobic and oleophobic PMMA and PMMA-coated glass surfaces fabricated by plasma processing. Microelectron. Eng. 2014, 121, 33-38. [CrossRef]

16. Zhu, J.; Hsu, C.-M.; Yu, Z.; Fan, S.; Cui, Y. Nanodome solar cells with efficient light management and self-cleaning. Nano Lett. 2010, 10, 1979-1984. [CrossRef] [PubMed]

17. Deng, X.; Mammen, L.; Zhao, Y.; Lellig, P.; Müllen, K.; Li, C.; Butt, H.-J.; Vollmer, D. Transparent, Thermally Stable and Mechanically Robust Superhydrophobic Surfaces Made from Porous Silica Capsules. Adv. Mater. 2011, 23, 2962-2965. [CrossRef] [PubMed]

18. Du, K.; Jiang, Y.; Huang, P.; Ding, J.; Gao, T.; Choi, C.-H. Self-formation of polymer nanostructures in plasma etching: Mechanisms and applications. J. Micromech. Microeng. 2018, 28, 014006. [CrossRef]

19. Mouterde, T.; Lehoucq, G.; Xavier, S.; Checco, A.; Black, C.T.; Rahman, A.; Midavaine, T.; Clanet, C.; Quéré, D. Antifogging abilities of model nanotextures Timothée Mouterde. Nat. Mater. 2017, 6, 658-663. [CrossRef] [PubMed]

20. Milionis, A.; Loth, E.; Bayer, I.S. Recent advances in the mechanical durability of superhydrophobic materials. Adv. Colloid Interface Sci. 2016, 229, 57-79. [CrossRef] [PubMed]

21. Ellinas, K.; Tserepi, A.; Gogolides, E. Durable superhydrophobic and superamphiphobic polymeric surfaces and their applications: A review. Adv. Colloid Interface Sci. 2017, 250, 132-157. [CrossRef] [PubMed]

22. Bayer, I.S. On the Durability and Wear Resistance of Transparent Superhydrophobic Coatings. Coatings 2017, 7, 12. [CrossRef]

23. Bayer, I.S.; Krishnan, K.G.; Robison, R.; Loth, E.; Berry, D.H.; Farrell, T.E.; Crouch, J.D. Thermal Alternating Polymer Nanocomposite (TAPNC) Coating Designed to Prevent Aerodynamic Insect Fouling. Sci. Rep. 2016, 6, 38459. [CrossRef] [PubMed]

24. Gao, L.; McCarthy, T.J. Contact angle hysteresis explained. Langmuir 2006, 22, 6234-6237. [CrossRef] [PubMed]

25. Young, T. An essay on the cohesion of fluids. Philos. Trans. R. Soc. Lond. 1805, 95, 65-87. [CrossRef]

26. Wenzel, R.N. Resistance of solid surfaces to wetting by water. Ind. Eng. Chem. 1936, 28, 988-994. [CrossRef]

27. Cassie, A.B.D.; Baxter, S. Wettability of porous surfaces. Trans. Faraday Soc. 1944, 40, 546-555. [CrossRef]

28. Gao, L.; McCarthy, T.J. The "lotus effect" explained: Two reasons why two length scales of topography are important. Langmuir 2006, 22, 2966-2967. [CrossRef] [PubMed]

29. Li, L.; Roethel, S.; Breedveld, V.; Hess, D.W. Creation of low hysteresis superhydrophobic paper by deposition of hydrophilic diamond-like carbon films. Cellulose 2013, 20, 3219-3226. [CrossRef]

30. Paxson, A.T.; Varanasi, K. Self-similarity of contact line depinning from textured surfaces. Nat. Commun. 2013, 4, 1492. [CrossRef] [PubMed]

31. Teisala, H.; Tuominen, M.; Aromaa, M.; Stepien, M.; Saarinen, J.M.; Toivakka, M.; Kuusipol, J. Nanostructures increase water droplet adhesion on hierarchically rough superhydrophobic surfaces. Langmuir 2012, 28, 3138-3145. [CrossRef] [PubMed]

32. Balu, B.; Breedveld, V.; Hess, D.W. Fabrication of "roll-off" and "sticky" superhydrophobic cellulose surfaces via plasma processing. Langmuir 2008, 24, 4785-4790. [CrossRef] [PubMed]

33. Yeong, Y.H.; Milionis, A.; Loth, E.; Bayer, I.S. Microscopic receding contact line dynamics on pillar and irregular superhydrophobic surfaces. Sci. Rep. 2014, 5, 8384. [CrossRef] [PubMed]

34. Schutzius, T.M.; Jung, S.; Maitra, T.; Graeber, G.; Köhme, M.; Poulikakos, D. Spontaneous droplet trampolining on rigid superhydrophobic surfaces. Nature 2015, 527, 82-85. [CrossRef] [PubMed]

35. Tuteja, A.; Choi, W.; Ma, M.; Mabry, J.M.; Mazzella, S.A.; Rutledge, G.C.; McKinley, G.H.; Cohen, R.E. Designing superoleophobic surfaces. Science 2007, 318, 1618-1622. [CrossRef] [PubMed]

36. Liu, T.L.; Kim, C.-J.C. Turning a surface superrepellent even to completely wetting liquids. Science 2014, 346, 1096-1100. [CrossRef] [PubMed] 
37. Yao, X.; Gao, J.; Song, Y.; Jiang, L. Superoleophobic surfaces with controllable oil adhesion and their application in oil transportation. Adv. Funct. Mater. 2011, 21, 4270-4276. [CrossRef]

38. Liu, M.; Wang, S.; Wei, Z.; Song, Y.; Jiang, L. Bioinspired Design of a Superoleophobic and Low Adhesive Water/Solid Interface. Adv. Mater. 2009, 21, 665-669. [CrossRef]

39. Pan, S.; Kota, A.K.; Mabry, J.M.; Tuteja, A. Superomniphobic surfaces for effective chemical shielding. J. Am. Chem. Soc. 2013, 135, 578-581. [CrossRef] [PubMed]

40. Yang, J.; Zhang, Z.; Men, X.; Xu, X.; Zhu, X. A Simple Approach to Fabricate Superoleophobic Coatings. New J. Chem. 2011, 35, 576-580. [CrossRef]

41. Rangel, T.C.; Michels, A.F.; Horowitz, F.; Weibel, D.E. Superomniphobic and easily repairable coatings on copper substrates based on simple immersion or spray processes. Langmuir 2015, 31, 3465-3472. [CrossRef] [PubMed]

42. Zhang, J.; Seeger, S. Polyester materials with superwetting silicone nanofilaments for oil/water separation and selective oil absorption. Adv. Funct. Mater. 2011, 21, 4699-4704. [CrossRef]

43. Yang, J.; Zhang, Z.; Xu, X.; Men, X.; Zhu, X.; Zhou, X. Superoleophobic textured aluminum surfaces. New J. Chem. 2011, 35, 2422-2426. [CrossRef]

44. Onda, T.; Shibuichi, S.; Satoh, N.; Tsujii, K. Super-water-repellent fractal surfaces. Langmuir 1996, 12, 2125-2127. [CrossRef]

45. Shibuichi, S.; Onda, T.; Satoh, N.; Tsujii, K. Super water-repellent surfaces resulting from fractal structure. J. Phys. Chem. 1996, 100, 19512-19517. [CrossRef]

46. Seo, J.; Lee, S.; Lee, J.; Lee, J.S.; Kwon, H.; Cho, S.; Ahn, J.-H.; Lee, T. Path-programmable water droplet manipulations on an adhesion controlled Superhydrophobic surface. Sci. Rep. 2015, 5, 12326. [CrossRef] [PubMed]

47. Zhang, X.; Shi, F.; Niu, J.; Jiang, Y.; Wang, Z. Superhydrophobic surfaces: From structural control to functional application. J. Mater. Chem. 2008, 18, 621-633. [CrossRef]

48. Nosonovsky, M.; Bhushan, B. Superhydrophobic surfaces and emerging applications: Non-adhesion, energy, green engineering. Curr. Opin. Colloid Interface Sci. 2009, 14, 270-280. [CrossRef]

49. Cao, L.; Jones, A.K.; Sikka, V.K.; Wu, J.; Gao, D. Anti-icing superhydrophobic coatings. Langmuir 2009, 25, 12444-12448. [CrossRef] [PubMed]

50. Yao, X.; Song, Y.; Jiang, L. Applications of bio-inspired special wettable surfaces. Adv. Mater. 2011, 23, 719-734. [CrossRef] [PubMed]

51. Shin, S.; Lee, J.; Lee, S.; Kim, H.; Seo, J.; Kim, D.; Hong, J.; Lee, S.; Lee, T. A Droplet-Based High-throughput SERS platform on a droplet-guiding-track-engraved superhydrophobic substrate. Small 2017, 13, 1602865. [CrossRef]

52. Shang, H.M.; Wang, Y.; Limmer, S.J.; Chou, T.P.; Takahashi, K.; Cao, G.Z. Optically transparent superhydrophobic silica-based films. Thin Solid Films 2005, 472, 37-43. [CrossRef]

53. Sahoo, B.N.; Sabarish, B.; Balasubramanian, K. Controlled fabrication of non-fluoropolymer composite film on glass surfaces with hierarchically nano structured fibers. Prog. Org. Coat. 2014, 77, 904-907. [CrossRef]

54. He, Z.; Ma, M.; Lan, X.; Chen, F.; Wang, K.; Deng, H.; Zhang, Q.; Fu, Q. Fabrication of a transparent superamphiphobic coating with improved stability. Soft Matter 2011, 7, 6435. [CrossRef]

55. Xu, L.; Karunakaran, R.G.; Guo, J.; Yang, S. Transparent, superhydrophobic surfaces from one-step spin coating of hydrophobic nanoparticles. ACS Appl. Mater. Interfaces 2012, 4, 1118-1125. [CrossRef] [PubMed]

56. The Economist. Available online: http://www.economist.com/node/21553480 (accessed on 28 April 2012).

57. Cho, K.L.; Liaw, I.I.; Wu, A.H.F.; Lamb, R.N. Influence of roughness on a transparent superhydrophobic coating. J. Phys. Chem. C 2010, 114, 11228-11233. [CrossRef]

58. Vourdas, N.; Tserepi, A.; Gogolides, E. Nanotextured Super-hydrophobic transparent poly(methyl methacrylate) surface using high-density plasma processing. Nanotechnology 2007, 18, 125304. [CrossRef]

59. Teshima, K.; Sugimura, H.; Inoue, Y.; Takai, O.; Takano, A. Transparent ultra water-repellent poly(ethylene terephthalate) substrates fabricated by oxygen plasma treatment and subsequent hydrophobic coating. Appl. Surf. Sci. 2005, 244, 619-622. [CrossRef]

60. Hikita, M.; Tanaka, K.; Nakamura, T.; Kajiyama, T.; Takahara, A. Super-liquid-repellent surfaces prepared by colloidal silica nanoparticles covered with fluoroalkyl groups. Langmuir 2005, 21, 7299-7302. [CrossRef] [PubMed] 
61. Dufour, R.; Harnois, M.; Coffinier, Y.; Thomy, V.; Boukherroub, R.; Senez, V. Engineering sticky superomniphonic surfaces on transparent and flexible PDMS substrate. Langmuir 2010, 26, 17242-17247. [CrossRef] [PubMed]

62. Irzh, A.; Ghindes, L.; Gedanken, A. Rapid deposition of transparent super-hydrophobic layers on various surfaces using microwave plasma. ACS Appl. Mater. Interfaces 2011, 3, 4566-4572. [CrossRef] [PubMed]

63. Tadanaga, K.; Kitamuro, K.; Matsuda, A.; Minami, T. Formation of superhydrophobic alumina coating films with high transparency on polymer substrates by the sol-gel method. J. Sol-Gel Sci. Technol. 2003, 26, 705-708. [CrossRef]

64. Im, M.; Im, H.; Lee, J.-H.; Yoon, J.-B.; Choi, Y.-K. A Robust Superhydrophobic and superoleophobic surface with inverse-trapezoidal microstructures on a large transparent flexible substrate. Soft Matter 2010, 6, 1401-1404. [CrossRef]

65. Tsui, K.-H.; Lin, Q.; Chou, H.; Zhang, Q.; Fu, H.; Qi, P.; Fan, Z. Low-Cost, Flexible, and self-cleaning 3D nanocone anti-refl ection films for high-efficiency photovoltaics. Adv. Mater. 2014, 26, 2805-2811. [CrossRef] [PubMed]

66. Kong, J.-H.; Kim, T.-H.; Kim, J.H.; Park, J.-K.; Lee, D.W.; Kimac, S.-H.; Kim, J.-M. Highly flexible, transparent and self-cleanable superhydrophobic films prepared by a facile and scalable nanopyramid formation technique. Nanoscale 2014, 6, 1453-1461. [CrossRef] [PubMed]

67. Lee, Y.-J.; Ruby, D.S.; Peters, D.W.; McKenzie, B.B.; Hsu, J.W.P. ZnO nanostructures as efficient antireflection layers in solar cells. Nano Lett. 2008, 8, 1501-1505. [CrossRef] [PubMed]

68. Huang, Y.-F.; Chattopadhyay, S.; Jen, Y.-J.; Peng, C.-Y.; Liu, T.-A.; Hsu, Y.-K.; Pan, C.-L.; Lo, H.-C.; Hsu, C.-H.; Chang, Y.-H.; et al. Improved broadband and quasi-omnidirectional anti-reflection properties with biomimetic silicon nanostructures. Nat. Nanotechnol. 2007, 2, 770-774. [CrossRef] [PubMed]

69. Tang, Y.-H.; Huang, M.-J.; Su, J.-Y.; Shiao, M.-H. Fabrication of nanocone subwavelength antireflection structures on quartz substrates. Jpn. J. Appl. Phys. 2012, 51, 06FF06. [CrossRef]

70. Su, R.; Liu, H.; Kong, T.; Song, Q.; Li, N.; Jin, G.; Cheng, G. Tuning surface wettability of $\operatorname{In}_{x} \operatorname{Ga}_{(1-x)} \mathrm{N}$ nanotip arrays by phosphonic acid modification and photoillumination. Langmuir 2011, 27, 13220-13225. [CrossRef] [PubMed]

71. D’Urso, B.; Simpson, J.T.; Kalyanaraman, M. Emergence of superhydrophobic behavior on vertically aligned nanocone arrays. Appl. Phys. Lett. 2007, 90, 044102. [CrossRef]

72. Hang, T.; Hu, A.; Ling, H.; Li, M.; Mao, D. super-hydrophobic nickel films with micro-nano hierarchical structure prepared by electrodeposition. Appl. Surf. Sci. 2010, 256, 2400-2404. [CrossRef]

73. Tiwari, J.N.; Chen, T.-M.; Pan, F.-M.; Lin, K.-L. Ordered silicon nanocones as a highly efficient platinum catalyst support for direct methanol fuel cells. J. Power Sources 2008, 182, 510-514. [CrossRef]

74. Fujii, T.; Gao, Y.; Sharma, R.; Hu, E.L.; DenBaars, S.P.; Nakamura, S. Increase in the extraction efficiency of GaN-based light-emitting diodes via surface roughening. Appl. Phys. Lett. 2004, 84, 855-857. [CrossRef]

75. Chen, Y.; Xu, Z.; Gartia, M.R.; Whitlock, D.; Lian, Y.; Liu, G.L. Ultrahigh throughput silicon nanomanufacturing by simultaneous reactive ion synthesis and etching. ACS Nano 2011, 5, 8002-8012. [CrossRef] [PubMed]

76. Yang, M.; Qu, F.; Lu, Y.; He, Y.; Shen, G.; Yu, R. platinum nanowire nanoelectrode array for the fabrication of biosensors. Biomaterials 2006, 27, 5944-5950. [CrossRef] [PubMed]

77. Xu, Z.; Chen, Y.; Gartia, M.R.; Jiang, J.; Liu, G.L. Surface plasmon enhanced broadband spectrophotometry on black silver substrates. Appl. Phys. Lett. 2011, 98, 241904. [CrossRef]

78. Kravets, V.G.; Schedin, F.; Grigorenko, A.N. Plasmonic blackbody: Almost complete absorption of light in nanostructured metallic coatings. Phys. Rev. B 2008, 78, 205405. [CrossRef]

79. Søndergaard, T.; Novikov, S.M.; Holmgaard, T.; Eriksen, R.L.; Beermann, J.; Han, Z.; Pedersen, K.; Bozhevolnyi, S.I. Plasmonic black gold by adiabatic nanofocusing and absorption of light in ultra-sharp convex grooves. Nat. Commun. 2012, 3, 969. [CrossRef] [PubMed]

80. Toma, M.; Loget, G.; M, R. Corn, Fabrication of broadband antireflective plasmonic gold nanocone arrays on flexible polymer films. Nano Lett. 2013, 13, 6164-6169. [CrossRef] [PubMed]

81. Toma, M.; Loget, G.; Corn, R.M. Flexible teflon nanocone array surfaces with tunable superhydrophobicity for self-cleaning and aqueous droplet patterning. ACS Appl. Mater. Interfaces 2014, 6, 11110-11117. [CrossRef] [PubMed]

82. Berthier, J. Micro-Drops and Digital Microfluidics, 2nd ed.; William Andrew: Norwich, NY, USA, 2012. 
83. Choi, K.; Ng, A.H.; Fobel, R.; Wheeler, A.R. Digital microfluidics. Annu. Rev. Anal. Chem. 2012, 5, 413-440. [CrossRef] [PubMed]

84. Yan, Y.; Gao, N.; Barthlott, W. Mimicking natural superhydrophobic surfaces and grasping the wetting process: A review on recent progress in preparing superhydrophobic surfaces. Adv. Colloid Interface Sci. 2011, 169, 80-105. [CrossRef] [PubMed]

85. Zhang, Y.-L.; Xia, H.; Kim, E.; Sun, H.-B. Recent developments in superhydrophobic surfaces with unique structural and functional properties. Soft Matter 2012, 8, 11217-11231. [CrossRef]

86. Bhushan, B.; Jung, Y.C. Natural and biomimetic artificial surfaces for superhydrophobicity, self-cleaning, low adhesion, and drag reduction. Prog. Mater. Sci. 2011, 56, 1-108. [CrossRef]

87. Liu, K.; Tian, Y.; Jiang, L. Bio-inspired superoleophobic and smart materials: Design, fabrication, and application. Prog. Mater. Sci. 2013, 58, 503-564. [CrossRef]

88. Darmanin, T.; Guittard, F. Wettability of conducting polymers: From superhydrophilicity to superoleophobicity. Prog. Polym. Sci. 2014, 39, 656-682. [CrossRef]

89. Wong, T.-S.; Kang, S.H.; Tang, S.K.; Smythe, E.J.; Hatton, B.D.; Grinthal, A.; Aizenberg, J. Bioinspired self-repairing slippery surfaces with pressure-stable omniphobicity. Nature 2011, 477, 443-447. [CrossRef] [PubMed]

90. Wang, Z.; Yuan, L.; Wang, L.; Wu, T. Stretchable superlyophobic surfaces for nearly-lossless droplet transfer. Sens. Actuators B 2017, 244, 649-654. [CrossRef]

91. Hsu, S.-H.; Woan, K.; Sigmund, W. Biologically Inspired Hairy Structures for Superhydrophobicity. Mater. Sci. Eng. R 2011, 72, 189-201. [CrossRef]

92. Roach, P.; Shirtchliffe, N.J.; Newton, M.I. Progress in superhydrophobic surface development. Soft Matter 2008, 4, 224-240. [CrossRef]

93. Celia, E.; Darmanin, T.; Givenchy, E.T.; Amigoni, S.; Guittard, F. Recent advances in designing superhydrophobic surfaces. J. Colloid Interface Sci. 2013, 402, 1-18. [CrossRef] [PubMed]

94. Nosonovsky, M.; Bhushan, B. Hierarchical roughness makes superhydrophobic states stable. Microelectron. Eng. 2007, 84, 382-386.

95. Sahoo, B.N.; Kandasubramanian, B. Recent progress in fabrication and characterisation of hierarchical biomimetic superhydrophobic structures. RSC Adv. 2014, 4, 22053. [CrossRef]

96. Xu, M.; Lu, N.; Xu, H.; Qi, D.; Wang, Y.; Shi, S.; Chi, L. Fabrication of flexible superhydrophobic biomimic surfaces. Soft Matter 2010, 6, 1438-1443. [CrossRef]

97. Ko, H.; Zhang, Z.; Takei, K.; Javey, A. Hierarchical polymer micropillar arrays decorated with ZnO nanowires. Nanotechnology 2010, 21, 295305. [CrossRef] [PubMed]

98. Lee, Y.; Park, S.-H.; Kim, K.-B.; Lee, J.-K. Fabrication of hierarchical structures on a polymer surface to mimic natural superhydrophobic surfaces. Adv. Mater. 2007, 19, 2330-2335. [CrossRef]

99. Xu, M.; Lu, N.; Qi, D.; Xu, H.; Wang, Y.; Shi, S.; Chi, L. Fabrication of superhydrophobic polymer films with hierarchical silver microbowl array structures. J. Colloid Interface Sci. 2011, 360, 300-304. [CrossRef] [PubMed]

100. Kim, T.-H.; Ha, S.-H.; Jang, N.-S.; Kim, J.; Kim, J.H.; Park, J.-K.; Lee, D.-W.; Lee, J.; Kim, S.-H.; Kim, J.-M. Simple and cost-effective fabrication of highly flexible, transparent superhydrophobic films with hierarchical surface design. ACS Appl. Mater. Interfaces 2015, 7, 5289-5295. [CrossRef] [PubMed]

101. Lee, J.-H.; Choi, W.-S.; Lee, K.-H.; Yoon, J.-B. A simple and effective fabrication method for various 3D microstructures: Backside 3D diffuser lithography. J. Micromech. Microeng. 2008, 18, 125015. [CrossRef]

102. Gong, D.; Long, J.; Jiang, D.; Fan, P.; Zhang, H.; Li, L.; Zhong, M. Robust and stable transparent superhydrophobic polydimethylsiloxane films by duplicating via a femtosecond laser-ablated template. Appl. Mater. Interfaces 2016, 8, 17511-17518. [CrossRef] [PubMed]

103. Lee, W.-K.; Jung, W.-B.; Nagel, S.R.; Odom, T.W. Stretchable superhydrophobicity from monolithic, threedimensional hierarchical wrinkles. Nano Lett. 2016, 16, 3774-3779. [CrossRef] [PubMed]

104. Vullers, F.; Gomard, G.; Preinfalk, j.; Klampaftis, E.; Worgull, M.; Richards, B.; Holscher, H.; Kavalenka, M.N. Bioinspired superhydrophobic highly transmissive films, for optical applications. Small 2016, 12, 6144-6152. [CrossRef] [PubMed]

105. Wong, W.S.Y.; Liu, G.; Nasiri, N.; Hao, C.; Wang, Z.; Tricoli, A. Omnidirectional self-assembly of transparent superoleophobic nanotextures. ACS Nano 2017, 11, 587-596. [CrossRef] [PubMed] 
106. Golovin, K.; Lee, D.H.; Mabry, J.M.; Tuteja, A. Transparent, flexible, superomniphobic surfaces with ultra-low contact angle hysteresis. Angew. Chem. Int. Ed. 2013, 52, 13007-13011. [CrossRef] [PubMed]

107. Li, Y.; Zhang, Z.; Wang, M.; Men, X.; Xue, Q. Environmentally safe, substrate-independent and repairable nanoporous coatings: Large-scale preparation, high transparency and antifouling properties. J. Mater. Chem. A 2017, 5, 20277-20288. [CrossRef]

108. Gao, Y.; Gereige, I.; El Labban, A.; Cha, D.; Isimjan, T.T.; Beaujuge, P.M. Highly transparent and UV-resistant superhydrophobic $\mathrm{SiO}_{2}$-coated $\mathrm{ZnO}$ nanorod arrays. Appl. Mater. Interfaces 2014, 6, 2219-2223. [CrossRef] [PubMed]

109. Wang, Y.; Shi, Y.; Pan, L.; Yang, M.; Peng, L.; Zong, S.; Shi, Y.; Yu, G. Multifunctional superhydrophobic surfaces templated from innately microstructured hydrogel matrix. Nano Lett. 2014, 14, 4803-4809. [CrossRef] [PubMed]

110. De Francisco, R.; Tiemblo, P.; Hoyos, M.; González-Arellano, C.; García, N.; Berglund, L.; Synytska, A. multipurpose ultra and superhydrophobic surfaces based on oligodimethylsiloxane-modified nanosilica. ACS Appl. Mater. Interfaces 2014, 6, 18998-19010. [CrossRef] [PubMed]

111. Guo, J.; Fang, W.; Welle, A.; Feng, W.; Filpponen, I.; Rojas, O.J.; Levkin, P.A. Superhydrophobic and slippery lubricant-infused flexible transparent nanocellulose films by photoinduced thiol-ene functionalization. ACS Appl. Mater. Interfaces 2016, 8, 34115-34122. [CrossRef] [PubMed]

112. Rahmawan, Y.; Xu, L.B.; Yang, S. Self-assembly of nanostructures towards transparent, superhydrophobic surfaces. J. Mater. Chem. A 2013, 1, 2955-2969. [CrossRef]

113. Seo, J.; Lee, J.S.; Lee, K.; Kim, D.; Yang, K.; Shin, S.; Mahata, C.; Jung, H.B.; Lee, W.; Cho, S.-W.; et al. Switchable Water-Adhesive, Superhydrophobic Palladium-Layered Silicon Nanowires Potentiate the Angiogenic Efficacy of Human Stem Cell Spheroids. Adv. Mater. 2014, 26, 7043-7050. [CrossRef] [PubMed]

114. Clapham, P.B.; Hutley, M.C. Reduction of lens reflexion by the "moth eye" principle. Nature 1973, 244, 281-282. [CrossRef]

115. Ibn-Elhaj, M.; Schadt, M. Optical polymer thin films with isotropic and anisotropic nano-corrugated surface topologies. Nature 2001, 410, 796-799. [CrossRef] [PubMed]

116. Zhang, X.-X.; Cai, S.; You, D.; Yan, L.-H.; Lv, H.-B.; Yuan, X.-D.; Jiang, B. Template-free sol-gel preparation of superhydrophobic ORMOSIL films for double-wavelength broadband antireflective coatings. Adv. Funct. Mater. 2013, 23, 4361-4365. [CrossRef]

117. Sinha, K.; Basu, M.; Pradhan, M.; Sarkar, S.; Pal, T. Fabrication of large-scale hierarchical ZnO hollow spheroids for hydrophobicity and photocatalysis. Chem. A Eur. J. 2010, 16, 7865-7874. [CrossRef] [PubMed]

118. Mondal, C.; Ganguly, M.; Sinha, A.K.; Pal, J.; Pal, T. Fabrication of a ZnO nanocolumnar thin film on a glass slide and its reversible switching from a superhydrophobic to a superhydrophilic state. RSC Adv. 2013, 3, 5937-5944. [CrossRef]

119. Hu, Z.W.; Li, W. Preparation of superhydrophobic $\mathrm{Fe}_{2} \mathrm{O}_{3}$ nanorod films with the tunable water adhesion. J. Colloid Interface Sci. 2012, 376, 245-249. [CrossRef] [PubMed]

120. Fukada, K.; Nishizawa, S.; Shiratori, S. Antifouling property of highly oleophobic substrates for solar cell surfaces. J. Appl. Phys. 2014, 115, 103516. [CrossRef]

121. Freschauf1, L.R.; McLane1, J.; Sharma, H.; Khine, M. Shrink Induced superhydrophobic and antibacterial surfaces in consumer plastics. PLoS ONE 2012, 7, e40987. [CrossRef] [PubMed]

122. Choi, S.J.; Huh, S.Y. Direct structuring of a biomimetic anti-reflective, self-cleaning surface for light harvesting in organic solar cells. Macromol. Rapid Commun. 2010, 31, 539-544. [CrossRef] [PubMed]

123. Kim, D.; Seo, J.; Shin, S.; Lee, S.; Lee, K.; Cho, H.; Shim, W.; Lee, H.-B.-R.; Lee, T. Reversible liquid adhesion switching of superamphiphobic Pd-decorated ag dendrites via gas-induced structural changes. Chem. Mater. 2015, 27, 4964-4971. [CrossRef]

124. Jiang, L.; Park-Lee, K.J.; Clinton, R.M.; Tang, Z.; Breedveld, V.; Hess, D.W. Mechanical durability of liquid repellent coatings. Surf. Coat. Technol. 2017, 328, 182-191. [CrossRef]

125. Liu, K.; Yao, X.; Jiang, L. Recent developments in bio-inspired special wettability. Chem. Soc. Rev. 2010, 39, 3240-3255. [CrossRef] [PubMed]

126. Nishimoto, S.; Bhushan, B. Bioinspired self-cleaning surfaces with superhydrophobicity, superoleophobicity, and superhydrophilicity. RSC Adv. 2013, 3, 671-690. [CrossRef]

127. Lau, C.; Butenhoff, J.L.; Rogers, J.M. The developmental toxicity of perfluoroalkyl acids and their derivatives. Toxicol. Appl. Pharmacol. 2004, 198, 231-241. [CrossRef] [PubMed] 
128. Ellis, D.A.; Mabury, S.A.; Martin, J.W.; Muir, D.C. Thermolysis of fluoropolymers as a potential source of halogenated organic acids in the environment. Nature 2001, 412, 321-324. [CrossRef] [PubMed]

129. Prevedouros, K.; Cousins, I.T.; Buck, R.C.; Korzeniowski, S.H. Sources, fate and transport of perfluorocarboxylates. Environ. Sci. Technol. 2006, 40, 32-44. [CrossRef] [PubMed]

130. Mates, J.E.; Ibrahim, R.; Vera, A.; Guggenheim, S.; Qin, J.; Calewarts, D.; Waldroup, D.E.; Megaridis, C.M. Environmentally safe and transparent superhydrophobic coatings. Green Chem. 2016, 18, 2185-2192. [CrossRef]

(c) (C) 2018 by the authors. Licensee MDPI, Basel, Switzerland. This article is an open access article distributed under the terms and conditions of the Creative Commons Attribution (CC BY) license (http://creativecommons.org/licenses/by/4.0/). 